NBER WORKING PAPER SERIES

\title{
EXPERIENCE MATTERS: \\ HUMAN CAPITAL AND DEVELOPMENT ACCOUNTING
}

\author{
David Lagakos \\ Benjamin Moll \\ Tommaso Porzio \\ Nancy Qian \\ Todd Schoellman \\ Working Paper 18602
}

http://www.nber.org/papers/w18602

\author{
NATIONAL BUREAU OF ECONOMIC RESEARCH \\ 1050 Massachusetts Avenue \\ Cambridge, MA 02138 \\ December 2012
}

We thank Daron Acemoglu, Mark Aguiar, Paco Buera, Francesco Caselli, Thomas Chaney, Sylvain Chassang, Angus Deaton, Mike Golosov, Fatih Guvenen, Lutz Hendricks, Erik Hurst, Joe Kaboski, Nobu Kiyotaki, Pete Klenow, Jonathan Parker, Richard Rogerson, Paul Romer, Sam Schulhofer-Wohl, David Sraer, David Weil and Fabrizio Zillibotti for their insights; the participants at the Princeton Macro Faculty Lunch, World Bank Macro Seminar, Rochester Macro Seminar, LSE Macro Seminar, EIEF Summer Seminar, EUI Macro Seminar, Columbia Development Seminar, Harvard Macro Seminar, Harvard/MIT Development seminar, Warwick Development Seminar, UQAM Macro Seminar, Laval Macro Seminar, Chicago Applied Workshop, USC Macro Seminar, CUNY Macro Seminar, SED Annual Meetings, NBER Summer Institute Growth Workshop, NBER Summer Institute EFG, BREAD, NEUDC, DFG conferences and the Conference on Human Capital at Washington University in St. Louis for useful comments. We thank Xin Meng for providing us with extracts from the Chinese Urban Household Surveys; and Anne Case and the RPDS for sharing their data from Taiwan and South Africa. The views expressed herein are those of the authors and do not necessarily reflect the views of the National Bureau of Economic Research.

NBER working papers are circulated for discussion and comment purposes. They have not been peerreviewed or been subject to the review by the NBER Board of Directors that accompanies official NBER publications.

(C) 2012 by David Lagakos, Benjamin Moll, Tommaso Porzio, Nancy Qian, and Todd Schoellman. All rights reserved. Short sections of text, not to exceed two paragraphs, may be quoted without explicit permission provided that full credit, including $(\mathbb{C}$ notice, is given to the source. 
Experience Matters: Human Capital and Development Accounting

David Lagakos, Benjamin Moll, Tommaso Porzio, Nancy Qian, and Todd Schoellman

NBER Working Paper No. 18602

December 2012, Revised October 2014

JEL No. O11,O4,O57

\section{ABSTRACT}

We use international household-survey data to document that experience-wage profiles are flatter in poorer countries than in richer countries. We find a quantitatively similar pattern when we estimate returns to foreign experience by country of origin among U.S. immigrants. The most likely explanation for both findings is that workers accumulate less human capital from experience in poorer countries. Taking this into consideration in development accounting substantially increases the role of human capital in accounting for cross-country income differences.

David Lagakos

Department of Economics, 0508

University of California, San Diego

9500 Gilman Drive

La Jolla, CA 92093

and NBER

lagakos@ucsd.edu

Benjamin Moll

Department of Economics

Princeton University

106 Fisher Hall

Princeton, NJ 08544

and NBER

moll@princeton.edu

Tommaso Porzio

Yale University

28 Hillhouse Ave.

New Haven, CT 06520

tommaso.porzio@yale.edu
Nancy Qian

Department of Economics

Yale University

27 Hillhouse Avenue

New Haven, CT 06520-8269

and NBER

nancy.qian@yale.edu

Todd Schoellman

Department of Economics

W.P. Carey School of Business

Arizona State University

P.O. Box 873806

Tempe, AZ 85287

todd.schoellman@gmail.com 


\section{Introduction}

Understanding the determinants of cross-country income differences is one of the central aims of growth and development economics. An important first step in addressing this difficult question is development accounting, which assesses how much of these income differences are due to observable factors of production, namely physical and human capital. The consensus in this literature is that human and physical capital together account for less than half of cross-country income differences (Klenow and Rodriguez-Clare, 1997; Hall and Jones, 1999; Caselli, 2005; Hsieh and Klenow, 2010). In other words, more than half of world income inequality is accounted for by residual total factor productivity (TFP).

To measure aggregate human capital stocks, most existing studies have focused on human capital acquired through schooling. A few studies have considered human capital acquired through experience, but have concluded that it does not improve the explanatory power of human capital (Klenow and Rodriguez-Clare, 1997; Bils and Klenow, 2000, 2002; Caselli, 2005). The reason is that the data employed in these studies showed little difference in the average level of experience across countries, and no relationship between the return to experience and income per capita (Psacharopoulos, 1994; Bils and Klenow, 2000, 2002).

This paper uses international household-survey data to document that experience-wage profiles are flatter in poor countries than in rich countries. We find a similar pattern when we estimate returns to foreign experience by country of origin among U.S. immigrants. The most likely explanation of our findings is that workers in poor countries accumulate less human capital from experience than their counterparts in rich countries. When we integrate this into an otherwise standard development accounting exercise, we find that human and physical capital now account for sixty percent instead of forty percent of crosscountry income differences.

To document our finding that experience-wage profiles are flatter in poor countries than in rich countries, we harmonize large-sample household-survey data from 35 countries from all income levels. These data provide several important benefits relative to previous studies, and, in particular, to the work of Psacharopoulos (1994) and those researchers relying on his estimates (e.g., Klenow and Rodriguez-Clare, 1997; Hall and Jones, 1999 and Caselli, 
2005). First, the large sample sizes allow us to estimate the returns to experience with minimal restrictions on functional form. Second, the comparable sampling frames across countries facilitate international comparisons. Finally, the availability of multiple cross sections spanning relatively long time periods in a number of countries allow us to control for cohort effects or time effects in our estimates. ${ }^{1}$

Throughout the paper, we follow the development accounting literature and focus on the returns to potential experience (henceforth, experience), defined as the number of years that have elapsed since an individual finished schooling. In our benchmark empirical analysis, we allow the returns to experience to vary fully flexibly for each additional year of experience. These estimates show that experience-wage profiles in poor countries typically lie below those of rich countries, i.e., the profiles are flatter in poor countries. We then demonstrate that this finding is robust to alternative sample restrictions, controls and definitions of experience.

A well-known challenge in estimating returns to potential experience is that, due to collinearity, one cannot separately identify the effects of potential experience (or age), birth cohort and time. Previous studies, such as Psacharopoulos (1994), abstracted from this issue entirely, presumably because they only had access to one cross section of data for most countries. We approach this challenge following the method proposed by Hall (1968) and Deaton (1997) for estimating returns to experience using repeated cross sections. For this exercise, we focus on the thirteen countries for which the data cover at least fifteen years from the earliest to most recent surveys. We consider three different versions of the Deaton-Hall approach, which make an additional assumption about whether growth is driven by time effects, such as general improvements in technology, or by cohort effects, such as improvements in the health of subsequent birth cohorts. We find that for some countries, such as China, the estimated returns to experience vary significantly under the different specifications. However, more importantly, we find that our main finding of steeper experience-wage profiles in rich countries is present under all three versions.

It is useful to divide interpretations of our cross-country findings into two categories.

\footnotetext{
${ }^{1}$ Many of the surveys available to Psacharopoulos (1994) and his collaborators were based on small sample sizes and/or non-representative samples. For example, his estimates for China and India are based on 145 and 507 observations, respectively.
} 
In the first category, differences in experience-wage profiles reflect different amounts of human capital accumulation across countries. The common theme in this category is that the profiles are informative about the productivity of workers across different levels of experience. In contrast, in the second category, differences in profiles capture differences in wage-setting institutions across countries. In other words, the profiles reflect characteristics of the countries unrelated to how worker productivity varies with experience.

To help distinguish between these two alternatives, we draw on evidence from U.S. immigrants, who all work in the same labor market. The data allow us to estimate returns to foreign experience, by country, for U.S. immigrants from 97 countries of all income levels. We find that the estimated returns to foreign experience are substantially higher among immigrants from rich countries than among those from poor countries. These patterns go against interpretations in which differences in experience-wage profiles are driven by crosscountry differences in capture differences in factors such as wage-setting institutions, since all immigrants are observed in the United States. Instead, they support interpretations in which workers in poor countries accumulate less human capital from experience than workers in rich countries. ${ }^{2}$

We conclude by showing what our findings imply for development accounting. Relative to the seminal work of Klenow and Rodriguez-Clare (1997), Hall and Jones (1999) and Caselli (2005), we relax only one assumption: we allow the returns to experience to vary across countries. Using the estimated experience-wage profiles, we show that the implied human capital due to experience is positively correlated with income and its cross-country dispersion is similar in magnitude to the dispersion of human capital due to schooling. Putting these together, we find that the contribution of physical and human capital to accounting for income differences increases from forty percent to around sixty percent. ${ }^{3}$

\footnotetext{
${ }^{2}$ In addition, data on the education and occupation of immigrants and non-migrants show little support for the possibility that our findings for immigrants are driven by differential selection or skill loss between immigrants from rich and poor countries. We discuss these data in Section 5.

${ }^{3}$ Our study is related to several others that measure aggregate human capital stocks using a broader definition than years of schooling. In particular, Weil (2007) and Shastry and Weil (2003) include the role of health, and Barro and Lee (2001), Hanushek and Kimko (2000), Hendricks (2002), Erosa et al. (2010), Schoellman (2012) and Manuelli and Seshadri (2014) include schooling quality. Jones (forthcoming) argues that allowing for imperfect substitutability across skill types leads to a larger role of human capital in development accounting. Gennaioli et al. (forthcoming) conduct a development accounting exercise for sub-national regions from many countries, and find a large role for human capital.
} 
This paper is organized as follows. Section 2 describes our household-survey data. Section 3 documents that experience-wage profiles are flatter in poor countries than in rich countries. Section 4 argues that there are two broad interpretations of our empirical finding: differences in human capital accumulation and differences in country-specific factors unrelated to human capital. Section 5 estimates experience-wage profiles for U.S. immigrants, which support the human capital interpretation. Section 6 conducts the development accounting exercise. Section 7 discusses development accounting under alternative assumptions. Section 8 concludes.

\section{Data}

Our analysis uses large-sample household survey data from 35 countries. The surveys we use satisfy two criteria: (i) they are nationally representative or representative of urban areas, and (ii) they contain data on labor income for at least five thousand individuals. We make use of multiple surveys for each country whenever data are available. The data cover 242 surveys, span the years 1970 to 2011, and cover 62,000 observations in the median country. The complete list of countries and data sources is listed in Section A.1 of the Appendix. The countries in our sample comprise a wide range of income levels, with the United States, Canada and Switzerland at the high end and Bangladesh, Vietnam and Indonesia at the low end. The main limitation in terms of data coverage is that we have no data for the very poorest countries in the world, such as those in Sub-Saharan Africa.

Our main outcome variable is an individual's wage, which we define to be her labor earnings divided by her hours worked. In most countries, we observe earnings over the month prior to the survey and hours worked over the week prior to the survey. In the few countries without hours data, we impute an individual's number of hours worked as the average number of hours across all other countries for that individual's experience level. We restrict attention to individuals with zero to forty years of experience who have positive labor income and non-missing age and schooling information. In all surveys, we impute the years of schooling using educational attainment data. For all countries, we express earnings and wages in local currency units of the most recent year for which we have a survey, using

the price deflators provided by the International Monetary Fund's International Financial 
Statistics. See Appendix A.1 of the for details on the data construction.

In our main analysis, we restrict attention to workers that are full-time wage earners, and exclude any workers with self-employed income. We exclude the self-employed for several reasons. First, evidence suggests that self-employed individuals tend to mis-report their income in surveys when asked directly (Deaton, 1997; Hurst et al., 2014). Second, the income of the self-employed conceptually consists of payments to both labor and to capital, which are difficult to distinguish in practice (Gollin, 2002). Third, self-employed income often accrues to the household rather than the individual, which makes it difficult to interpret self-employed income reported at the individual level. In Section 3.5, we show that when we nonetheless include the self-employed in countries where our data allow, the estimates of the returns to experience are similar.

In our main analysis, we define potential experience as experience $=$ age - schooling 6 for individuals with eight or more years of schooling and as experience $=$ age -14 for individuals with fewer than eight years of schooling. This definition implies that individuals begin to work at age fourteen or after they finish school, whichever comes later. The cutoff at age fourteen is motivated by the fact that we observe very few individuals with positive wage income before the age of fourteen in our countries (see Figure A.3 of the Appendix). Later, in Section 3.5, we show that our results are robust to several alternative definitions of potential experience, and are similar when we estimate age-wage profiles or experienceearnings profiles rather than experience-wage profiles.

\section{Returns to Experience Across Countries}

\subsection{Conceptual Framework}

We use a simple model of human capital, similar to the one proposed by Bils and Klenow (1998), to motivate our empirical estimation. Human capital of individual $i$, who is born in year $c$ and surveyed in time $t, h_{i c t}$, depends on schooling, $s_{i c t}$ and experience, $x_{i c t}$ :

$$
h_{i c t}=\exp \left(g\left(s_{i c t}\right)+f\left(x_{i c t}\right)\right)
$$


We further impose $f(0)=g(0)=0$, meaning that we normalize the human capital of a worker with zero years of both schooling and experience to be one. Thus, we focus on the part of human capital due to schooling or experience. ${ }^{4}$

For now, follow the development accounting literature and assume that workers earn their marginal products, supply their entire human capital to the labor market and that human capital is valued in efficiency units up to a mean-zero error term. These assumptions allow us to identify individual human capital stocks directly from individual wages. Later, in Section 4, we discuss departures from these assumptions.

Hence, an individual's hourly wage is equal to the product of her human capital, a skill price $\omega_{c t}$, and an error term $\varepsilon_{i c t}$ :

$$
w_{i c t}=\omega_{c t} h_{i c t} \exp \left(\varepsilon_{i c t}\right)
$$

We allow the skill price, $\omega_{c t}$, to differ across cohorts and time periods:

$$
\omega_{c t}=\bar{\omega} \exp \left(\gamma_{t}+\chi_{c}\right)
$$

where $\gamma_{t}$ and $\chi_{c}$, represent time- and cohort-specific determinants of labor productivity that are not captured by human capital due to schooling or experience. Time effects represent factors like cohort-neutral technical change and capital accumulation, and cohort effects reflect cohort-specific technical change and accumulation of cohort-specific capital. ${ }^{5}$ Substituting equations (1) and (3) into equation (2) and taking logs, we obtain

$$
\log w_{i c t}=\log \bar{\omega}+g\left(s_{i c t}\right)+f\left(x_{i c t}\right)+\gamma_{t}+\chi_{c}+\varepsilon_{i c t} .
$$

Thus, a worker's wage is a function of: her years of schooling and experience, $s_{i c t}$ and $x_{i c t}$;

\footnotetext{
${ }^{4}$ The choice of an additively separable specification in schooling and experience has the benefit that the returns to schooling and experience are independent of each other. We find similar results to those presented below when we allow interactions between schooling and experience; details are available upon request. We also show later in the paper that separability between schooling and experience is not necessary for identifying total human capital stocks.

${ }^{5}$ Cohort effects can also capture things like cohort-specific changes in health status, i.e. determinants of labor productivity that, as a matter of semantics, one may call "human capital." As already noted, however, the focus of our paper is on human capital due to schooling or experience. We therefore do not include cohort effects in our definition of human capital in (1).
} 
a vector of time-period dummy variables, $\gamma_{t}$; a vector of cohort dummy variables, $\psi_{c}$; and a mean-zero error term, $\varepsilon_{i c t}$. In this section, we estimate the function $f(\cdot)$ and assess how it varies across countries. Through the lens of the simple framework in this section, a flat experience-wage profile $f(\cdot)$ reflects low human capital accumulation over the lifecycle. Of course, experience-wage profiles may differ across countries for other reasons. We discuss these in detail in Section 4. Our first empirical exercise is to estimate equation (4) for each country under the assumption that there are no cohort or time effects, $\gamma_{t}=\chi_{c}=0$. Afterwards, we turn to richer specifications that consider cohort and time effects.

\subsection{Benchmark Results}

We begin our empirical analysis by allowing the relationship between experience and wages to vary for each year of experience. This flexible functional form fully accounts for changes in the slope of the experience-wage profile. We estimate

$$
\log w_{i c t}=\alpha+\theta s_{i c t}+\sum_{x=1}^{45} \phi_{x} D_{i c t}^{x}+\varepsilon_{i c t}
$$

where $D_{i c t}^{x}$ is a dummy variable that takes the value of one if a worker has $x$ years of experience. The coefficient $\phi_{x}$ estimates the average wage of workers with $x$ years of experience relative to the average wage of workers with zero years of experience. In terms of our notation from the previous section, the $\phi_{x}$ terms represent $f(x)$ such that the coefficient estimate corresponding to each experience level, $x$, identifies the experiencewage profile evaluated at point $x$.

Figure 1 displays the experience-wage profiles for three large countries in our sample: the United States, Mexico and India (see Figure A.2 for the estimated profiles for all countries). For brevity, we will use "steepness" to refer to the average slope of the profiles over all experience levels (as opposed to the point-wise slope at a given level of experience). The steepest profile among these three countries is in the United States, which is also the richest country of the three. Mexico has the next steepest profile, followed by India. ${ }^{6}$

Figure 1 also shows that the cross-country differences in the profiles are mostly realized

\footnotetext{
${ }^{6}$ The confidence intervals tend to be tight for most countries, so we omit them for brevity; see Figure A.3 for the confidence intervals for India, Mexico and the United States. Note that our experience-wage profiles for the United States are quite similar to others in the literature (e.g., Lemieux, 2006).
} 
by twenty years of experience, which is also approximately the average experience level of most countries in our sample. Therefore, to illustrate the relationship between the steepness of the profiles and income for all of the countries in our sample, we plot the height of the estimated profiles evaluated at twenty years potential experience against the log of GDP per capita at PPP in 2010 in Figure 2. The figure shows the main empirical finding of our paper, which is that the experience-wage profiles in poor countries are systematically flatter than those in rich countries. The correlation between the height of the profiles at twenty years on log GDP per capita is 0.60 . The slope coefficient from a regression of the height at twenty years potential experience and log GDP per capita is 0.20 and is statistically significant at the one percent level. In terms of economic significance, the slope tells us that one log point higher GDP per capita - such as the United States relative to Mexico - is associated with twenty percent higher returns to the first twenty years of potential experience. ${ }^{7}$

\subsection{Cohort and Time Effects}

The main challenge to estimating returns to experience (or age) is that one cannot separately identify the effects of experience, birth cohort and time, due to collinearity. In this section, we consider the effects of cohort and time controls following the approach proposed by Hall (1968) and Deaton (1997) for estimating returns to experience using repeated cross sections. ${ }^{8}$ We use data from the thirteen countries for which our data cover at least fifteen years: Bangladesh, Brazil, Canada, Chile, China, Germany, India, Indonesia, Italy, Jamaica, Mexico, the United Kingdom and the United States. The data cover 142 surveys and span an average of 26 years per country; see Appendix A.1 for the years employed for each country.

We consider three different versions of the Deaton-Hall approach. The first version

\footnotetext{
${ }^{7}$ We find a positive correlation between log GDP per capita and the heights of the profiles at ten, fifteen and thirty years potential experience as well. We also find similar results when using log of per capita GDP for the year which is the midpoint of the sample for each individual country, rather than 2010. These results are available upon request.

${ }^{8}$ Panel data afford no additional advantages relative to repeat cross sections as far as identifying experience, cohort and time effects is concerned. See for example Heckman and Robb (1985, p.140) who note that "it is by now well known (e.g. Cagan, 1965) that [longitudinal] data do not solve the identification problem," and that "panel data and a time series of cross sections of unrelated individuals are equally informative."
} 
attributes all labor productivity growth to cohort effects, and uses year dummies to capture only cyclical fluctuations. This is the assumption made in Deaton's (1997) original analysis and more recently by Aguiar and Hurst (2013). We implement this by estimating equation (5) with birth-cohort dummies and time dummies, with the restriction that the time dummies are orthogonal to a time trend. See Appendix A.2 for a more formal description of our methodology.

Figure 3 plots the predicted height of the profiles at twenty years of experience based on these estimates. As the figure shows, the correlation between income and steepness of profiles is still present. Table 1 shows that the correlation between the height of the profiles at twenty years of experience and log GDP per capita is still 0.42 , compared to 0.60 in the benchmark cross-sectional estimates. The slope coefficient is 0.14 under this version compared to 0.20 in the benchmark. Figure 3 also shows that the profiles for most countries are steeper in this version than in the cross-sectional estimates (Figure 2). The reason is that, in a growing economy, attributing all growth to cohort effects implies that older cohorts are less productive than younger cohorts. Thus, controlling for cohort effects causes experience-wage profiles to be steeper than in cross-sectional estimates. ${ }^{9}$

The second version takes the "opposite" extreme and attributes all labor productivity growth to time effects. We implement this by estimating equation (5) with cohort and time dummies, but now we restrict the cohort effects to be orthogonal to a time trend. Figure 4 plots the predicted profiles for the returns to experience. As the figure shows, the results are very similar to the cross-sectional profiles in Figure 1. Table 1 shows that the correlation between the height of the profiles at twenty years and income is 0.58 , just below the benchmark, and the slope coefficient is 0.13 . The reason that the profiles in this version appear more like the benchmark is that attributing all growth to time effects implies that older and younger cohorts have similar productivity. Thus, controlling for cohort effects has little impact on experience-wage profiles.

The third takes the intermediate view that productivity growth is attributed in equal parts to cohort and time effects. While we are agnostic on the most natural split between

\footnotetext{
${ }^{9}$ In Appendix A.2 we walk through the case of China, which becomes particularly steep, and hence is a useful case for understanding the mechanics of the controls.
} 
time and cohort effects, the case of an equal split is nonetheless useful for illustrating how estimated returns to experience across countries depend on the relative importance of the two effects. Figure 5 plots the predicted returns to twenty years experience in this case. For most countries, the experience-wage profiles lie somewhere between those in the previous two versions of the Deaton-Hall method. The correlation between log GDP per capita and the profile heights at twenty years of experience is 0.52 , and the slope coefficient is $0.13 .^{10}$

We conclude that for some countries, such as China, the estimated returns to experience vary significantly depending on the relative importance of cohort and time effects. However, as in the cross sectional estimates, experience-wage profiles in rich countries are steeper than those of poor countries in all three versions of the Deaton-Hall method we consider.

\subsection{Parsimonious Functional Form for Experience-Wage Profiles}

While the fully flexible estimates are useful for revealing the true functional form of the experience-wage relationship, a parsimonious approximation of the relationship is more convenient for several exercises that we will conduct in this paper (e.g., examining compositional effects) and for comparing our results to the existing development accounting literature. As can be seen in Figure 1, experience-wage profiles are highly non-linear, particularly in rich countries. A quadratic specification, such as used by Psacharopoulos (1994), therefore provides a poor approximation of the true profiles. ${ }^{11}$

Thus, for parsimony, we will measure experience using a quintic polynomial:

$$
\log w_{i c t}=\alpha+\theta s_{i c t}+\sum_{k=1}^{5} \phi_{k} x_{i c t}^{k}+\varepsilon_{i c t}
$$

where the $\log$ wage of individual $i$ of cohort $c$ during year $t$ is a function of her years of schooling, $s_{i c t}$, and her years of experience, $x_{i c t}$. This is the special case of equation (4) with $g(s)=\theta s$ and $f(x)=\sum_{k=1}^{5} \phi_{k} x^{k}$.

The estimated returns to experience appear very similar using the quintic specification

\footnotetext{
${ }^{10}$ We have also estimated profiles with either only time effects and no cohort effects, or only cohort effects and no time effects. This approach has been taken by a number of papers in the literature, including Guvenen (2007) and Huggett et al. (2011). The results here look quite similar to the first and second variants of the Deaton-Hall method, respectively, and are available upon request.

${ }^{11}$ The observation that a higher order polynomial is necessary for capturing the true profiles for rich countries such as the United States was made by Murphy and Welch (1990).
} 
as under the fully flexible specification. Furthermore, the cross-country relationship between returns to experience and log GDP per capita is almost the same using the quintic and fully flexible specifications, with a correlation of 0.56 in the former and 0.60 in the latter. Thus, we will mostly focus on the quintic specification henceforth.

\subsection{Robustness}

This section investigates the robustness of the experience-profile estimates.

Inclusion of the Self-Employed In the main analysis of the paper, we keep only wage earners and exclude any workers with self-employment income because of the measurement concerns raised in Section 2. In this section, we relax this restriction and include all workers with either wage income or self-employed income (or both), and take the income data of the self employed as given. We find that when we include the self employed in the twelve countries for which self-employed income data are available, the estimated returns to experience are virtually identical with and without the self-employed. For brevity, the results are shown in the Appendix, in Figure A.5.

As an additional robustness check, we regress the steepness of the profiles at twenty years of experience on GDP per capita and the fraction of workers that are self-employed as reported by the World Bank's World Development Indicators. The coefficient on GDP per capita is large (0.05) and statistically significant (standard error 0.0133), which means that income is positively associated with the steepness of the profiles for two countries with the same proportion of self-employed workers. Thus, the cross-country results are not only an artifact of the possibility that there are more self-employed workers in poor countries and self-employed workers have flatter profiles than other workers in poor countries. In contrast, the coefficient on the fraction self-employed is small in magnitude (0.007) and statistically insignificant (standard error 0.006). This means that for two countries with

the same income, there is no association between the share of self-employed workers and the height of the experience-wage profiles.

Other Sample Restrictions Thus far, our results include all individuals earning a wage and working full time, regardless of sex or sector of work. In addition, we do not restrict the age of individuals in our sample other than through the restriction that potential experience 
is positive. One potential concern is that our results are driven by cross-country differences in female labor supply, or the timing of female entry into or exit out of the labor force. Another concern is that workers in the public sector may earn wages that are not closely tied to market forces. Similarly, one may worry that wages for agricultural workers in poor countries are mis-measured. Finally, one may worry that our findings are driven by the inclusion of very young workers, or cross-country differences in the fraction of workers that are below a certain age.

To address these concerns, we repeat our estimates of the experience-wage profiles under several different sample restrictions. The first includes part-time workers in addition to full-time workers. The second and third restrict the sample to be only male workers and male private-sector workers. The fourth restricts the sample to be only non-agricultural workers. The last two restrict the sample by keeping only workers older than 18 , and only workers older than 22, respectively. Panel (a) of Table 2 presents the correlation between the height of the experience-wage profile and GDP per capita, as well as the coefficient from a regression of the former on the latter, under these alternative sample restrictions. The correlation in the benchmark estimate from Section 3.2 is 0.60 . Under the alternative sample restrictions, the correlations range from 0.43 to 0.59 and are all significant at the $5 \%$ level or lower. The slope in the benchmark is 0.20 and significant at the one percent level, while the slopes range from 0.14 to 0.24 under the alternative restrictions and all significant at the five percent level or lower. We conclude that none of these restrictions makes an appreciable difference to our main result.

Experience Definition Our main exercise assumes that individuals start work when they finish schooling or reach fourteen years of age, whichever comes sooner. Panel (b) of Table 2 reports the correlation for two alternative definitions of potential experience.

The first of these makes the more standard assumption, made by Caselli (2005), that all workers begin work at age six or whenever they finish schooling and hence sets $e x$ perience $=$ age - schooling -6 . The second assumes that all workers begin work at age fifteen or whenever they finish schooling, which is another plausible assumption given our observations in Figure A.3, and hence sets experience $=$ age - schooling -6 for all indi- 
viduals with nine or more years of schooling, and experience $=$ age -15 for other workers. The correlations between the heights at 20 years of potential experience and log GDP per capita are 0.50 and 0.59 in the two cases, and the slope coefficient of a regression of the former on the latter are 0.17 and 0.21 respectively. Thus, our main result is not an artifact of our choice of definition for potential experience.

Experience-Earnings Profiles and Age-Wage Profiles One widely studied alternative to experience-wage profiles are experience-earnings profiles. In our data, these two variables are highly correlated and the the slope of the experience-earnings profiles is steeper than that of the experience-wage profiles. Thus, cross-country differences in experience-earnings profiles are even more substantial than cross-country differences in experience-wage profiles. The reason for this is that hours worked increase over the lifecycle at a faster rate in richer countries than poorer countries, at least in our set of countries. Another alternative to experience-wage profiles are age-wage profiles. In our data, these profiles are also flatter in poor countries than in rich countries. ${ }^{12}$

Returns to Schooling One concern is that our estimated returns to experience lead to implausible returns to schooling, or returns to schooling that differ from the literature in a substantial way. In the Appendix, we show that this is not the case. ${ }^{13}$

Related is the question of whether our result for the returns to experience is an artifact of our choice for estimating the returns to schooling. To investigate this, we first estimate the returns to experience under the restriction that returns to schooling satisfy the nonlinear function used by Hall and Jones (1999). In particular, this is that the first four years of schooling have a thirteen percent return, the next four have a ten percent return, and all others have a seven percent return. We then estimate the returns to experience by restricting the returns to schooling to be a constant ten percent, following the exercise of Hsieh and Klenow (2010), which assumes this return in all countries. The slope coefficient

\footnotetext{
${ }^{12}$ Appendix Figure A.11 plots the heights of experience-earnings profiles against log GDP per capita for our set of countries. Appendix Figure A.12 plots the heights of the age-wage profiles at age forty.

${ }^{13}$ See Appendix Figure A.8, which that shows the estimated returns to schooling for the countries in our sample. They range from three percent to seventeen percent per year of schooling with a mean return of nine percent. The figure also shows that the return to schooling is at best weakly correlated with GDP per capita. This is consistent with previous estimates. See Hsieh and Klenow (2010) and the references within.
} 
from a regression of the heights at 20 years of experience and the log of GDP per capita is 0.21 in both cases. For brevity, this is not presented in tables. This is quite similar to the 0.20 found in our benchmark case. Thus, our main result does not appear to be an artifact of the way we estimate returns to schooling relative to the literature.

Additional Sensitivity Tests In addition to the robustness checks presented in this section, we conducted many others that we do not discuss for brevity. For example, we provide evidence that our results are not driven by measurement error in age or schooling; see Section A.4 of the Appendix. We also find that our results are robust to different functional forms for estimating the returns to schooling, in particular higher order polynomials and fully flexible returns to education; alternative imputation methods for hours worked in countries with no hours data; restricting the sample to only include household heads; restricting the maximum years of experience to be fifty years; and using the Current Population Survey in the United States instead of the Census. ${ }^{14}$

\section{Interpretation}

There are two categories of explanations for why experience-wage profiles are steeper in richer countries. The first stipulates that workers tend to accumulate less human capital from experience in poor countries than in rich countries. This could happen exogenously: perhaps the characteristics of the work done, the technology used, or the way workers interact leads to less human capital in poor countries. ${ }^{15}$ It could also happen endogenously: perhaps institutions, credit constraints or low TFP lead workers to choose endogenously lower investment in life-cycle human capital. ${ }^{16}$ Note that in this latter case human capi-

\footnotetext{
${ }^{14}$ We also examine the extent to which the estimated cross-country differences in experience-wage profiles are due to differences in worker compositions across countries. We find little support that our findings are accounted for by differences in returns to experience among broad industry groups, schooling level, sex or urban-rural status. See Appendix A.3.

${ }^{15}$ For example, the models of Lucas (2009), Lucas and Moll (2011), and Perla and Tonetti (2011) posit that human capital is accumulated through social interactions with others; all determinants of the frequency or quality of such interactions are potential determinants of cross-country differences in returns to experience.

${ }^{16}$ In the models of Erosa et al. (2010) and Manuelli and Seshadri (2014), low TFP in poor countries depresses the returns to the accumulation of human capital by raising the price of physical inputs to human capital production. Similarly, extractive institutions in poor countries (emphasized by e.g. Acemoglu et al. (2001)) may discourage workers from investing in human capital, since their returns be confiscated in one way or another (Bhattacharya et al., 2013). This logic is consistent with recent evidence that higher taxation of labor income in Europe can explain a substantial fraction of European-U.S. differences in wage inequality and lifecycle wage growth (Guvenen et al., 2014). If workers cannot borrow to smooth consumption, they may not take jobs that offer good training opportunities. This could be formalized in
} 
tal from experience accounts for cross-country income differences only in the development accounting sense; there can still be a deeper causal force that, in turn, explains why experience profiles in poor countries are flatter. Either way, all of these explanations emphasize that flatter experience-wage profiles indicate lower rates of human capital accumulation.

The second category of explanations does not rely on cross-country differences in human capital. Instead, they stipulate that differences in country-specific factors such as wage setting institutions or matching frictions lead to different experience-wage profiles. ${ }^{17}$ What is important for our purposes is that any explanation in this category suggests that experience profiles do not reflect human capital accumulation, and that they should not be considered as explanatory factors for cross-country income differences, even in the development accounting sense. Thus, it is important for our purposes to distinguish whether our findings have an explanation in the first or the second category. In the next section we provide evidence that helps us make this distinction.

\section{$5 \quad$ Evidence from U.S. Immigrants}

In this section, we turn to U.S. immigrants to help interpret the returns to experience we estimate above. Studying U.S. immigrants offers several advantages. First, the workers are all observed in a common labor market, as opposed to a diverse set of economies with varying labor market conditions and institutions. Second, data for all workers come from a common source, the U.S. census, which alleviates potential concerns about cross-country data comparability. At the same time, studying immigrants presents challenges as well, since immigrants are selected non-randomly, and may not have their skills transfer well into the U.S. labor market. We address these challenges below. We find that estimated returns

a framework in the spirit of Galor and Zeira (1993), but with on-the-job investment in human capital. More generally, the same factors which cause firms to grow less quickly over the lifecycle in poor countries (Hsieh and Klenow, 2012) may explain why workers' earnings grow less quickly; Seshadri and Roys (2012) propose such a theory.

${ }^{17}$ In this category are theories in which workers and firms agree to long-term contracts where wages do not equal workers' marginal products (see e.g., Azariadis, 1988; Lazear, 1979; Michelacci and Quadrini, 2009). In many such theories, frictions such as moral hazard or limited commitment on the part of workers lead firms to "backload" wages, leading experience-wage profiles to be steeper than the true relationship between the marginal product of labor and experience. If these frictions are more pronounced in poor countries, our estimates would understate the difference in lifecycle human capital accumulation between rich and poor countries. But other theories of long-term contracting also suggest reasons for front-loading of wage-contracts in poor countries. Also in this category are theories in which there are matching frictions in labor markets (Burdett, 1978; Jovanovic, 1979; Burdett and Mortensen, 1998) that differ systematically in rich and poor countries. 
to experience among U.S. immigrants are substantially higher among workers from rich countries than among those from poor countries, and that the most likely interpretation is lower human capital accumulation from experience among workers in poor countries.

\subsection{Data}

Our data on immigrants are from the 1980-2000 U.S. Population Censuses and the 2005-2012 American Community Surveys (ACSs), downloaded from IPUMS. Each of these data sets includes a large, representative cross-section of the U.S. population. We identify immigrants using the country of birth. Our datasets also include information on the year of immigration, from which we can compute the number of years each immigrant has been in the United States. ${ }^{18}$

We construct potential experience using information on age and educational attainment. We define experience and impute years of schooling from educational attainment data exactly as in Section 2. For immigrants, we split their experience into foreign (birth country) and domestic (U.S.) experience. As in the main analysis, we exclude workers with more than 40 years of total experience. We also exclude those with 35 years of foreign experience or more, or those who enter the United States before completing their schooling.

As before, we restrict attention to full-time wage workers. We construct the hourly wage using information on annual wage and salary income for the prior year, usual hours worked per week, and weeks worked in the prior year. Finally, we use three Census-provided controls in our analysis. The first is the state of residence, which is designed to help capture the large cross-state differences in the cost of living that would otherwise bias our results. The second is English-language ability. The Census has included a self-reported measure of English language ability throughout this time, with five options ranging from "Does not speak English" to "Yes, speaks only English." We further parse the data by creating a sixth category for U.S. born persons, so that the remaining categories all capture variation within the immigrant population. The last control is a gender dummy. Further details about our immigrant data and estimation are provided in Appendix A.5.

\footnotetext{
${ }^{18}$ We find that most immigrants report being in their country of birth immediately before migrating: 87 percent report being in their birth country five years before migrating and 83 percent report being their one year before migrating. There also appears to be no systematic relationship between this secondary migration and GDP per capita.
} 


\subsection{Returns to Experience Among New Immigrants}

We begin by estimating returns to foreign experience among new immigrants, which we define as immigrants that arrived in the United States in the year prior to a census. The advantage of looking at new immigrants is that they have a negligible amount of U.S. work experience. Thus we can estimate the returns to foreign experience, for each country, without having to consider interaction effects between foreign and U.S. experience. To ensure that we have enough observations on new immigrants, we consider all countries for which we have at least 1,000 new immigrants.

We posit that the wage $w_{i t}$ for worker $i$ in time period $t$ satisfies

$$
\log \left(w_{i t}\right)=\alpha+\theta s_{i t}+\sum_{k=1}^{4} \phi_{k}\left(x_{i t}\right)^{k}+\delta Z_{i t}+\varepsilon_{i t},
$$

where $s_{i t}$ are her years of schooling, $x_{i t}$ are her years of foreign potential experience, and $Z_{i t}$ are other controls. We estimate this by pooling natives and immigrants from all countries, allowing the following terms to vary by country: the constant, $\alpha$, the return to schooling, $\theta$, the polynomial in foreign experience, $\phi_{k}$, and dummies for the decade of arrival in the United States. We also include dummies for sex, state and English language ability, and a time effect. Note that since we include country fixed effects, the reference worker in each country is an immigrant from the country in question with no foreign experience. ${ }^{19}$

In Figure 6, we present the estimated returns to experience from equation (7) using one simple summary statistic: the predicted return to the first twenty years foreign experience. We plot this statistic for each country against the country's GDP per capita in 2010. One can see that the returns to foreign experience vary positively with GDP per capita. The simple linear regression line has a slope of 0.25 , and is significant at the one percent level. We conclude that among new immigrants, returns to foreign experience are higher for immigrants from richer countries than those from poorer countries. Of course, the number of countries in our analysis is only 25; in the following section we include all immigrants, not just new immigrants, which allows us to consider a larger set of countries. ${ }^{20}$

\footnotetext{
${ }^{19}$ Our identification strategy uses the standard solutions found in the literature on immigrants. An extended discussion is found in Appendix A.5.

${ }^{20}$ While our paper is the first to estimate the returns to U.S. immigrant experience by income level of the
} 


\subsection{Returns to Experience Among All Immigrants}

We now consider returns to experience using the entire sample of immigrants in our data. In general, these immigrants have potential experience that accrued in their source county and potential experience that accrued in the United States. Our preferred approach is to control separately for foreign experience and U.S. experience using a quadratic polynomial for each, and include also a quadratic interaction term between U.S. and foreign experience. This allows us to estimate the returns to foreign experience for immigrants from each country, while parsimoniously controlling for U.S. experience. Because of the large number of immigrants working in the United States, our sample contains over 1.5 million immigrants covering 97 countries for which we have at least 1,000 immigrants. ${ }^{21}$

Letting $x_{i t}$ and $x_{i t}^{U S}$ be the amount of foreign experience and U.S. experience of worker $i$ in time $t$, we assume this worker's wage satisfies:

$$
\log \left(w_{i t}\right)=\alpha+\theta s_{i t}+\sum_{k=1}^{4}\left(\phi_{k}\left(x_{i t}\right)^{k}+\phi_{k}^{U S}\left(x_{i t}^{U S}\right)^{k}\right)+\sum_{n=1}^{2} \sum_{m=1}^{2} \psi_{n m}\left(x_{i t}\right)^{n}\left(x_{i t}^{U S}\right)^{m}+\delta Z_{i t}+\varepsilon_{i t} .
$$

As before, we estimate this equation by pooling natives and immigrants from all countries, allowing the following terms to vary by country: the constant, $\alpha$, the return to schooling, $\theta$, the quartic polynomial in foreign experience, $\phi_{k}$, the quadratic interaction terms, $\psi_{n m}$, as well as dummies for the decade of arrival in the United States. We again include dummies (not country specific) for sex, state, time and English language ability.

Figure 7 plots the predicted returns to twenty years of foreign experience (and no U.S. experience) among immigrants for each countries in our data against the log of GDP per capita. It shows that the returns to foreign experience are generally higher for immigrants from rich countries than for immigrants from poor countries. The slope coefficient from

source country, our findings build on several prior studies. Chiswick (1978) uses earlier U.S. data and finds that returns to experience tend to be lower for immigrants from poorer regions of the world. Coulombe et al. (Forthcoming) find that in Canada there are also lower returns to experience for Canadian immigrants from poorer countries. Schoellman (2012) estimates returns to schooling among U.S. immigrants and uses that to draw inferences about quality of schooling around the world, but his paper does not consider returns to experience. Note that the estimated country-specific returns to schooling of Schoellman (2012) are virtually identical to the country-specific returns to schooling we estimate using equation (7) in the current paper. Both sets of estimates show lower returns to schooling on average in poor countries than in rich countries.

${ }^{21}$ For most countries we have many more observations: we have 48 countries with at least 5,000 immigrants and 28 countries with at least 10,000 immigrants for example. 
a regression of the return to twenty years foreign experience on log GDP per capita is 0.19, and is statistically significant at the one percent level. In Table A.2 in the Appendix, we show that this positive and significant slope is present under a number of alternative sample restrictions.

\subsection{Comparing Returns to Experience for Immigrants and Stayers}

We now compare returns to experience for immigrants to individuals from the same country that did not migrate abroad. For expositional purposes, we refer to these individuals as stayers. Specifically, we compare the returns to experience that we estimate for stayers in Section 3 to our returns estimated for immigrants from equation (8). There are 32 countries for which we have both sets of estimates.

Figure 8 plots the predicted returns to twenty years experience against log GDP per capita for the immigrants and stayers. Both estimates show a strong positive relationship with GDP per capita, with higher returns to experience, on average, in the economies with higher GDP per capita. Among immigrants, the slope coefficient is 0.19 , with a P-value less than 0.001. For stayers, the slope coefficient is 0.21 and the P-value is also less than 0.001 . One can also see that immigrant returns to foreign experience are on average somewhat lower than returns of stayers. The correlation between the two sets of is 0.65 .

The simplest possible explanation of Figure 8 is that workers in poor countries accumulate less human capital from experience than workers in richer countries, since this explanation can account for both the findings for stayers and immigrants simultaneously. In contrast, theories of the findings for stayers working through country differences in wage-setting institutions need to appeal to separate explanations for the two sets of findings. For example, assume that we believe that workers in all countries accumulate similar amounts of human capital from experience, but that labor-market institutions present in poor countries lead high-experience workers there to earn less than their marginal products. Then this may potentially account for the lower measured returns to experience among stayers in poor countries than stayers in rich countries. But it does not explain the immigrant findings, and hence one needs a second explanation for them. In the next section we examine two such potential explanations. 


\subsection{Comparing Other Characteristics of Immigrants and Stayers}

Previous work in the immigration literature has considered two additional factors that may affect returns to experience for immigrants: selection and skill loss. Our main concern is that selection or skill loss works differently for immigrants from poor and rich countries, and that this differential selection or skill loss explains why returns to experience vary with GDP per capita. Appendix A.6 presents a simple model that formalizes these two hypotheses; below we explain them each informally.

To address each of these possibilities, we combine our evidence from immigrants with data on non-migrants from a large set of countries for which appropriate data are available. In particular, we use data on stayers from IPUMS, using nationally representative survey data for all countries with internationally comparable data on years of schooling and occupation. The key difference between the data we use here and those used to estimate experience-wage profiles earlier in the paper is that those in the current section do not generally have information on wages.

We begin by addressing the hypothesis of differential selection. In short, this theory states that immigrants from rich countries are more positively selected (or less negatively selected) on ability to learn than immigrants from poor countries, where ability to learn is an individual trait that affects the human capital generated per year of potential experience. To test this hypothesis, we consider the average years of schooling for immigrants and nonmigrants. Our underlying assumption is that ability to learn will be positively correlated with duration of schooling, which allows us to make inferences about ability selection from data on school selection.

Figure 9 shows the results. The left-hand panel shows that average years of schooling among stayers is strongly correlated with log GDP per capita, with less than five years of schooling on average in the poorest countries and more than twelve years on average in the richest. In contrast, the right-hand panel shows that immigrants from countries of all income levels are highly educated on average, with the majority having roughly twelve years of schooling. These data do not support the differential selection hypothesis, because immigrants from poorer countries are actually much more positively selected on schooling 
attainment than are immigrants from richer countries.

We now turn to the hypothesis of differential skill loss. Briefly, this theory says that immigrants from rich countries can transfer more of their experience human capital to the U.S. than can immigrants from poor countries. To test this hypothesis, we compare rates of skill loss for immigrants and non-migrants. We define a worker to be experiencing skill loss if they have a college education (our notion of "skilled") but work in a low-skilled occupation. ${ }^{22}$ For each country, we calculate the fraction of all college-educated immigrants and stayers that work in high-skilled occupations.

Figure 10 plots the results. The left-hand panel shows that among stayers, a high fraction of college-educated workers are in high-skill jobs in countries of all income levels. The trend is positive with GDP per capita, meaning that college-educated workers in rich countries tend to work at high-skilled jobs with higher frequency. The right-hand panel shows that a large fraction of college-educated immigrants are employed at high-skilled jobs as well, and that the relationship is also increasing in GDP per capita of origin. It is clear that immigrants are less likely to work at high skilled jobs than stayers in countries of any income level. This is consistent with the presence of skill loss. However, the slopes for immigrants and stayers appear similar, suggesting that skills loss is present to a similar degree in countries of all income levels. This is evidence against the possibility that our findings are explained by differential skill loss.

We also investigate a more subtle form of differential selection or skill loss that operates through an association with experience. The idea here is that immigrants with more experience may be selected differently than those with less selection, and that the difference in how selected they are may be correlated with GDP per capita; a similar story works for skill loss. To test this, we compared selection or skill loss (as defined above) between low and high experience immigrants in our sample. We find no evidence that the difference in selection or skill loss between these groups is correlated with GDP per capita. These checks, when combined with the fact that returns to experience patterns are strongly correlated

\footnotetext{
${ }^{22}$ IPUMS has standardized occupation codes across all our data sources. We define high skilled to be "professionals," "technicians and associate professionals," and "legislators, senior officials and managers," and low skilled to be "clerks, service workers and shop and market sales," "skilled agricultural and fishery workers," "crafts and related trades workers," "plant and machine operators and assemblers" and "elementary occupations." We omit individuals in the armed forces or other unspecified or unreported occupations.
} 
with the same patterns for non-migrants, suggest that cross-country differences in human capital accumulation are the most plausible interpretation of the data.

\section{Development Accounting}

In this section, we illustrate the economic significance of our findings by applying them to a development accounting exercise. Our accounting exercise follows the previous literature, in particular the work of Klenow and Rodriguez-Clare (1997), Hall and Jones (1999) and Caselli (2005), in constructing measures of the aggregate physical and human capital stocks across countries using data on the average quantities and returns to schooling and potential experience. We depart from the previous literature by allowing the return to experience to differ across countries. We show that this one change increases the importance of physical and human capital in accounting for income differences from around forty percent to around sixty percent.

Conceptually, we differ from existing studies in the following way. Existing studies assume that the mapping between years of experience and human capital from experience is the same in all countries. We allow the mapping between years of experience and human capital from experience to vary across countries.

To measure human capital, we assume that the human capital of individual $i$ at time $t$ with schooling $s_{i t}$ and experience $x_{i t}$ is

$$
h_{i t}=\exp \left(g\left(s_{i t}\right)+f\left(x_{i t}\right)\right)
$$

which is the specification assumed by Bils and Klenow (2000). Studies such as those of Hall and Jones (1999) and Caselli (2005) posit the same equation but ignore the $f\left(x_{i t}\right)$ term and focus just on schooling. Given country-specific estimates of the wage returns experience, $f$, and schooling $g$, it is then easy to compute individual human capital stocks and to aggregate them. This is what we do next. 


\subsection{Aggregate Experience Human Capital}

We begin by decomposing individual human capital stocks into the components due to experience and schooling $h_{i t}=h_{i t}^{S} h_{i t}^{X}$, where

$$
h_{i t}^{X}=\exp \left(f\left(x_{i t}\right)\right), \quad h_{i t}^{S}=\exp \left(g\left(s_{i t}\right)\right),
$$

and $g$ and $f$ are estimated for each country in the wage regression (3). Analogously, we define the aggregate experience human capital stock per worker as the average of the individual stocks across individuals and over time

$$
H^{X}=\frac{1}{T} \sum_{t=1}^{T} \frac{1}{N_{t}} \sum_{i=1}^{N_{t}} h_{i t}^{X} .
$$

Our estimates for aggregate experience human capital stocks are simply the integral of the estimated experience-wage profiles from the previous section (i.e., the area beneath the wage profiles) using the distribution of work experience from the data. Computing human capital this way makes three assumptions that are standard in the development accounting literature: (i) workers earn their marginal products, (ii) workers supply their entire human capital to the labor market, and (iii) human capital is valued in efficiency units. These assumptions imply that a worker's human capital is proportional to his wage.

Figures 11a - 11d plot the implied experience human capital against per capita GDP for each country. For these figures, the experience human capital stocks are calculated using the quintic specification in equation (6), and each figure corresponds to a different restriction on cohort and year effects, analogous to Figures 1-5. These figures display a strong and significant relationship between human capital from experience and income levels. The estimates of experience human capital stocks for each country are available upon request. 


\subsection{Aggregate Human Capital from Both Schooling and Experience}

We define the total human capital stock per worker (due to both schooling and experience) in a country to be the average of individual human capital stocks:

$$
H=\frac{1}{T} \sum_{t=1}^{T} \frac{1}{N_{t}} \sum_{i=1}^{N_{t}} h_{i t} .
$$

The estimates of these human capital stocks are based on our estimated returns to schooling and experience from the quintic specification. Compare (10) and (11) and note that we are not decomposing the aggregate human capital stocks into a part due to schooling and a part due to experience. In particular, $H \neq H^{S} H^{X}$ (even though at the individual level $\left.h_{i t}=h_{i t}^{S} h_{i t}^{X}\right)$. Instead we are simply asking what human capital stocks would be if one were to only take into account schooling or only take into account experience.

Table 3 Panel (a) summarizes our country-specific estimates of aggregate human capital stocks and presents two measures of the cross-country distribution of total human capital stocks. The first measure we use is the log variation in human capital stocks and the second measure is the slope of a linear regression of log human capital stocks on log GDP per capita. The first measure is reported in column (1) and shows that simple dispersion of human capital stocks, as measured by the log variation, is somewhat larger for schooling than for experience, but both are of the same order of magnitude. The latter measure is reported in column (2) and shows that a one-percent increase in log GDP per capita corresponds to a 0.21-percent increase in human capital stock from experience. For the sake of comparison, we also present the increase in the human capital stock from schooling, which is 0.15 percent. These results show that experience and schooling contribute roughly equally to generate the differences in human capital stocks between rich and poor countries. ${ }^{23}$

Finally, the third row of Panel (a) in Table 3 reports the dispersion of total human

\footnotetext{
${ }^{23}$ Note that while cross-country differences in human capital due to schooling and experience are similar in magnitude, there is an important asymmetry in how those differences arise. In the case of schooling, it is well known that returns to a year of school completed are roughly similar across countries, while average years of schooling completed are higher in richer countries. For experience, as we document, returns to a year of experience are higher in rich countries, while the average level of experience does not vary substantially between countries (see Figure A.9 in the Appendix).
} 
capital stocks, where we take into account both schooling and experience. It shows that taking into account cross-country differences in returns to experience (going from row one to three) roughly doubles both the dispersion in human capital stocks across countries and the slope of the relationship between human capital stocks and GDP per capita. Panels (b), (c) and (d) of Table 3 show that these numbers change somewhat when we use the estimates from the three versions of the Deaton-Hall method, but that our main finding that allowing returns to experience to vary across countries increases cross-country human capital gaps - is always present.

\subsection{Development Accounting}

To make the development accounting exercise comparable to the existing development accounting literature, we use the same accounting method as in the survey by Caselli (2005). Our accounting procedure uses a Cobb-Douglas aggregate production function, $Y=K^{\alpha}(A H)^{1-\alpha}$, where $Y$ is a country's real GDP per worker, $K$ is its physical capital stock per worker, $A$ is total factor productivity, and $H$ is our measure of the aggregate human capital stock per worker. The capital share is assumed to equal one-third, $\alpha=1 / 3$, which is standard in this literature.

Following Caselli (2005), we calculate the measure:

$$
\text { success }_{1}=\frac{\operatorname{var}\left(\ln Y_{K H}\right)}{\operatorname{var}(\ln Y)},
$$

where $Y_{K H}=K^{\alpha} H^{1-\alpha}$ is the component of output due to factors of production. Intuitively, success 1 represents the fraction of actual variation in log output per worker that would be present if countries differed only by stocks of human and physical capital. Note that this measure does not take into account the correlation between $Y_{K H}$ and $Y$, and as such could be inflated by noisy estimates. For example, high measurement error in $Y_{K H}$ could be confounded with high explanatory power, since it artificially increases $\operatorname{var}\left(\ln Y_{K H}\right)$. In light of this caveat, we also report the slope of a regression of $\ln Y_{K H}$ on $\ln Y$.

Table 4 presents these measures when we calculate aggregate human capital stocks either from only schooling, from only experience or from both schooling and experience. 
Panel (a) shows the results using our cross-sectional estimates of human capital stocks. When human capital is measured by only using schooling as in most of the literature, success $_{1}$ is equal to 0.40 . Recall that in Table 3 , we showed that cross-country differences in experience human capital are roughly as big as those in schooling human capital. This is reflected in Table 4: the second row reveals that when human capital is measured only using experience, success $s_{1}$ is 0.40 . In other words, schooling and experience human capital taken alone are roughly equally important determinants of cross-country income differences. Finally, when both schooling and experience are taken into account, the measure of success increases substantially, up to 0.63. From the slope of the regression of $\ln Y_{K H}$ on $\ln Y$, reported in column (2), calculating human capital from both education and experience increases not only the total variability of $\ln Y_{K H}$ across countries, but also its correlation with $\ln Y$. Panels (b), (c) and (d) show that similar findings apply when we construct human capital using our estimates with controls for time or cohort effects. ${ }^{24}$

\section{Development Accounting under Alternative Models of Human Capital}

In this section, we illustrate how our development accounting conclusions change quantitatively under alternative models of human capital. In particular, we consider two departures from the simple conceptual framework in Section 3.1, on which the accounting exercise in the previous section is based. First, we consider how our development accounting results change if time investment plays an important role in human capital accumulation as in the Ben-Porath (1967) model. Second, we explore how imperfect substitutability between workers of varying experience levels affects our results.

\subsection{Experience-Wage Profiles with Time Investment}

The framework in Section 3.1 and our development accounting results are consistent with a number of theories of human capital accumulation, and in particular with theories in which human capital accumulates "passively" as a by-product of working. In contrast, we show here that if workers' time is an important investment into human capital accumulation, our development accounting results provide an upper bound on the importance

\footnotetext{
${ }^{24}$ In Appendix A.7 we illustrate the effects of each departure that we take from existing accounting exercises and their influences on our final results. In short, our results differ almost entirely because we allow returns to experience to differ across countries, and not because our data differ on other dimensions with the data used by previous studies.
} 
of lifecycle human capital differences across countries.

Consider a simple model of human capital accumulation where individuals can invest into human capital accumulation as in Ben-Porath (1967): $\dot{h}=F(h, \ell)$, where $\ell$ are time inputs into the production of human capital, $h(0)=1$ and $F$ is a smooth function. Assuming that an individual has a time endowment of one, her wage is given by

$$
w(t)=\bar{\omega}(1-\ell(t)) h(t) \exp (\varepsilon)
$$

The individual is considered to be in school if $\ell(t)=1$. In Ben-Porath type models, the time paths for $\ell(t)$ are obtained from individuals' optimizing behavior. Before discussing the determinants of these choices, we begin with a simple case that takes these time paths as given and is further instructive because it maps back to our empirical model in Sections 3 and 6 exactly:

$$
\dot{h}=F(h, \ell)= \begin{cases}\theta(\ell) h, & \ell=1 \\ \phi(\ell) h, & \ell<1 .\end{cases}
$$

Here, $\theta(\ell)$ is the marginal return in terms of human capital during school and $\phi$ is the return during school. It is easy to show that

$$
\log h(t)=g(s)+\tilde{f}(x)
$$

where $s$ denotes years spent in school, $x=t-s$ years of experience, and $g(s)$ and $\tilde{f}(x)$ are the cumulative returns to schooling and experience. ${ }^{25}$ Substituting into equation (13) yields an equation linking wages, schooling and potential experience that has the same form as our estimating equation (3)

$$
\log w=\log \bar{\omega}+g(s)+\underbrace{\log (1-\ell(x))+\tilde{f}(x)}_{f(x)}+\varepsilon,
$$

where $f(x)$ is the estimated experience-wage profile. In Ben-Porath type models, there

\footnotetext{
${ }^{25}$ These cumulative returns are defined as $g(s) \equiv \int_{0}^{s} \theta(\ell(\tilde{s})) d \tilde{s}$ and $f(x) \equiv \int_{0}^{x} \phi(\ell(\tilde{x})) d \tilde{x}$. Further note that (15) is the same functional form as our "human capital production function" (1) which is also the one used by Bils and Klenow (2000).
} 
are two reasons for upward-sloping experience-wage profiles. The first is human capital accumulation $(\tilde{f}(x)$ increases with each year of experience). The second is that workers may decrease the amount of time allocated towards human capital accumulation $(\ell(x)$ is decreasing with each year of experience). Empirically, one cannot separately identify these two channels and our estimated experience-wage profiles, $f(x)$, would reflect both. ${ }^{26}$ If, in contrast, human capital investment took the form of goods investment rather than time investment, or if human capital was simply accumulated passively as in learning-by-doing models, this problem would not arise.

The implication for development accounting is that in Ben-Porath type models with time investment, one cannot infer increases in human capital from experience-wage profiles alone. Thus, under these theories, the development accounting conclusions of the previous section are an upper bound on the importance of lifecycle human capital differences.

\subsection{Quantitative Role of Human Capital Investment Time}

The goal of this section is to quantitatively disentangle increases in human capital from decreases in investment time through the lens of a Ben-Porath model. We can then re-do our standard development accounting exercise using the human capital stocks implied by the model, and ask whether there are still substantial differences in these stocks across countries.

For simplicity, we consider a simplified version of the model above in which time is the only factor in producing human capital. In particular, we assume that human capital accumulates according to $\dot{h}=\varphi(\ell) h$, where $\ell$ is the worker's time spent investing in new human capital. We assume further that $\varphi(\ell)=B \ell^{\gamma}-\delta$, where $B$ and $\gamma$ govern efficiency and returns to scale in human capital investment and $\delta$ is the depreciation rate of existing capital. Finally, we assume away human capital accumulation during schooling. Workers solve the problem

$$
\max _{\ell(t), t \geqq 0} \int_{0}^{T} e^{-r t}[\omega(1-\tau(t)) h(t)(1-\ell(t))] d t,
$$

\footnotetext{
${ }^{26}$ We thank Lutz Hendricks for first pointing this out to us. Relative to a standard development accounting exercises like ours, the Ben-Porath model departs from the assumption that workers supply their entire human capital to the labor market. See also Kuruscu (2006) who argues that, in the United States, much of the steepness of experience-wage profiles is explained by a decreasing fraction of time allocated towards human capital accumulation.
} 
subject to $\dot{h}=\varphi(\ell) h$, where $\tau(t)$ is a "wedge" that determines the human capital accumulation decision over time. These wedges can be thought of as any factor which gives workers a disincentive to accumulate more human capital, and which potentially varies with a worker's potential experience (in this case, $t$ ).

To quantify the importance of human capital investment time for measuring crosscountry experience human capital stocks, we proceed as follows. We first assume that the human capital production function is the same in all countries. Next, we pick the $\tau(t)$ paths for each country to match the country's experience-wage profile exactly. Finally, we recover the implied paths for investment and human capital, $\ell(t)$ and $h(t)$, for each country. In Section A.8 of the Appendix, we show how this can be done in the current framework by using the fact that optimizing workers will choose not to invest in the final period, i.e. $\ell(T)=0$.

The parameter values we use in the quantitative exercise are $B=0.19, \gamma=0.94$ and $\delta=0$, which are taken from Manuelli and Seshadri's (2014) cross-country analysis of the Ben-Porath model. Their efficiency and scale parameters are disciplined to be consistent with the U.S. age-wage profiles and observed inputs to human capital production. Their depreciation rate is chosen based on the observation that wage profiles do not systematically decline at the end of the lifecycle. ${ }^{27}$

Appendix Figure A.10 presents the human capital and investment profiles for the United States, as an illustration. Early on, workers spend just over one-third of their time investing in human capital. Over the lifecycle, their investment time declines steadily until eventually reaching zero. Human capital increases rapidly over the lifecycle and then eventually levels off. The wage rise is steeper than the rise in human capital, reflecting both the increase in capital and the decrease in investment time. Countries with flatter experience-wage profiles differ in that they have less investment and smaller increases in human capital over the lifecycle.

\footnotetext{
${ }^{27}$ The interpretation of their scale parameter and our parameter $\gamma$ differs slightly. This is for two reasons: first, their formulation features both time and non-time inputs into human capital accumulation, whereas we abstract from the latter for simplicity. Second, we postulate an accumulation technology that is linear in human capital rather than being subject to slight diminishing returns. Both departures are made entirely for tractability, as they allow us to obtain analytic solutions for the time path of wages given time allocation decisions.
} 
When we redo the development accounting results using the experience human capital implied by the model, we find that success $_{1}$ rises to 0.50 , up from 0.40 in the world without experience human capital. This is lower than the 0.63 of the benchmark calculations, but still represents a substantial increase in the importance of factors. We also find that the slope of a regression of $\ln Y_{K H}$ on $\ln Y$ increases from 0.52 to 0.59 . This implies that adding human capital from experience still increases the correlation between actual income and income in a world with only factor differences.

In summary, when human capital is measured through the lens of a Ben-Porath model of human capital investment, the quantitative importance of experience human capital is lower than in our benchmark analysis. However, the main qualitative point of our study stands since importance of human capital in accounting for income differences is still substantially increased.

\subsection{Imperfect Substitutability Between Human Capital Types}

The development accounting exercise in Section 6 makes the assumption that human capital is measured in efficiency units, i.e. different skill types are perfect substitutes. Here, we briefly discuss how the introduction of imperfect substitutability would alter our results. Similar to Jones (forthcoming), we come to the conclusion that it would likely result in larger estimated cross-country gaps in human capital stocks. In our framework, this is because imperfect substitutability changes the mapping from the Mincer regression, equation (4), to the estimated human capital stocks. To see this, consider a variant of our development accounting framework in which the aggregate human capital stock $H$ depends on the human capital stocks $\tilde{H}(x, s)$ of different schooling- and experience-types as follows

$$
H=\left(\sum_{x, s} \tilde{H}(x, s)^{\frac{\sigma-1}{\sigma}}\right)^{\frac{\sigma}{\sigma-1}}, \quad 1<\sigma<\infty .
$$

This results in a non-constant skill price $\omega_{c t}(x, s)$. Under the assumption that different skill types consist of an equal number of people, one can show that the Mincer regression (4) becomes

$$
\log w_{i c t}=\log \bar{\omega}+\left(1-\frac{1}{\sigma}\right)\left(g\left(s_{i c t}\right)+f\left(x_{i c t}\right)\right)+\gamma_{t}+\chi_{c}+\varepsilon_{i c t} .
$$


With imperfect substitutability, $\sigma<\infty$, estimated returns to experience $\left(1-\frac{1}{\sigma}\right) f(\cdot)$ are always strictly smaller than true returns to experience $f(\cdot)$. Hence, imperfect substitutability would lead us to underestimate cross-country differences in returns to experience and hence human capital stocks. ${ }^{28}$

\section{Conclusion}

A large literature has concluded that human and physical capital account for less than half of cross-country income differences (Klenow and Rodriguez-Clare, 1997, Hall and Jones, 1999, Caselli, 2005). Probably because of data limitations, this literature has found that taking into account human capital from experience does not change the explanatory power of human and physical capital. This paper uses better data than what were available to earlier studies and documents that experience-wage profiles are steeper in rich countries than in poor countries. We also find that immigrants from richer countries have higher returns to foreign experience than immigrants from poorer countries. This suggests that the most plausible explanation for our cross-country results is that there are cross-country differences in human capital from experience. To assess the economic significance of our new finding, we conduct a development accounting exercise where we allow the return to experience to vary across countries. We find human and physical capital now account for sixty percent of income differences across countries, up from forty percent.

\footnotetext{
${ }^{28}$ More generally, if we relax the assumption that different skill types consist of an equal number of people, an additional term shows up in equation (18) capturing varying scarcity of different experience types as experience accumulates. Because experienced individuals are usually scarcer in poor countries this would likely lead us to underestimate cross-country differences in the true returns to experience even further.
} 


\section{References}

Acemoglu, Daron, Simon Johnson, and James A. Robinson, "The Colonial Origins of Comparative Development: An Empirical Investigation," American Economic Review, December 2001, 91 (5), 1369-1401.

Aguiar, Mark and Erik Hurst, "Deconstructing Lifecycle Expenditure," Journal of Political Economy, 2013, $9 \%$.

Azariadis, Costas, "Human Capital and Self-Enforcing Contracts," Scandinavian Journal of Economics, 1988, 90 (4), 507-28.

Barro, Robert J and Jong-Wha Lee, "International Data on Educational Attainment: Updates and Implications," Oxford Economic Papers, July 2001, 53 (3), 541-63.

Ben-Porath, Yoram, "The Production of Human Capital and the Life Cycle of Earnings," Journal of Political Economy, 1967, 75, 352.

Bhattacharya, Dhritman, Nezih Guner, and Gustavo Ventura, "Distortions, Endogenous Managerial Skills and Productivity Differences," Review of Economic Dynamics, January 2013, 16 (1), 11-25.

Bils, Mark and Peter J. Klenow, "Does Schooling Cause Growth or the Other Way Around?," NBER Working Papers 6393, National Bureau of Economic Research February 1998.

_ and _ , "Does Schooling Cause Growth?," American Economic Review, December 2000, $90(5), 1160-83$.

Borjas, George J., "Assimilation, Changes in Cohort Quality and the Earnings of Immigrants," Journal of Labor Economics, 1985, 3, 463-489.

Burdett, Kenneth, "A Theory of Employee Job Search and Quit Rates," The American Economic Review, 1978, 68 (1), pp. 212-220.

- and Dale T Mortensen, "Wage Differentials, Employer Size, and Unemployment," International Economic Review, May 1998, 39 (2), 257-73.

Cagan, Phillip, "Measuring Quality Changes and the Purchasing Power of Money: an Exploratory Study of Automobiles," The National Banking Review: a Journal of Policy and Practice, 1965.

Carroll, Christopher D. and Lawrence H. Summers, "Consumption Growth Parallels Income Growth: Some New Evidence," in "National Saving and Economic Performance" NBER Chapters, National Bureau of Economic Research, 1991, pp. 305-348.

Caselli, Francesco, "Accounting for Cross-Country Income Differences," in Philippe Aghion and Steven Durlauf, eds., Handbook of Economic Growth, Vol. 1, Elsevier, 00 2005, chapter 9, pp. 679-741.

Chiswick, Barry, "The Effect of Americanization on the Earnings of Foreign-Born Men," Journal of Political Economy, 1978, 86 (5), 897-921. 
Coulombe, Serge, Gilles Grenier, and Serge Nadeau, "Quality of Work Experience and Economic Development-Estimates Using Canadian Immigrant Data," Journal of Human Capital, Forthcoming.

Deaton, Angus, The Analysis of Household Surveys: A Microeconometric Approach to Development Policy, The World Bank, 1997.

Erosa, Andres, Tatyana Koreshkova, and Diego Restuccia, "How Important Is Human Capital? A Quantitative Theory Assessment of World Income Inequality," Review of Economic Studies, October 2010, 77 (4), 1421-1449.

Friedberg, Rachel M., "The Labor Market Assimilation of Immigrants in the United States: The Role of Age at Arrival," 1992. Unpublished Manuscript, Brown University.

Galor, Oded and Joseph Zeira, "Income Distribution and Macroeconomics," Review of Economic Studies, 1993, 60 (1), 35-52.

Gennaioli, Nicola, Rafael La Porta, Florencio Lopez-de-Silanes, and Andrei Shleifer, "Human Capital and Regional Development," Quarterly Journal of Economics, forthcoming.

Gollin, Douglas, "Getting Income Shares Right," Journal of Political Economy, April 2002, $110(2), 458-474$.

Guvenen, Fatih, "Learning Your Earning: Are Labor Income Shocks Really Very Persistent?," American Economic Review, June 2007, 97 (3), 687-712.

_ , Burhanettin Kuruscu, and Serdar Ozkan, "Taxation of Human Capital and Wage Inequality: A Cross-Country Analysis," Review of Economic Studies, 2014, 81 (2), 818850.

Hall, Robert E., "Technical Change and Capital from the Point of View of the Dual," The Review of Economic Studies, 1968, 35 (1), pp. 35-46.

- and Charles I. Jones, "Why Do Some Countries Produce So Much More Output Per Worker Than Others?," The Quarterly Journal of Economics, February 1999, 114 (1), 83-116.

Hanushek, Eric A. and Dennis D. Kimko, "Schooling, Labor-Force Quality, and the Growth of Nations," American Economic Review, December 2000, 90 (5), 1184-1208.

Heckman, James and Richard Robb, "Using Longitudinal Data to Estimate Age, Period and Cohort Effects in Earnings Equations," in William M. Mason and Stephen E. Fienberg, eds., Cohort Analysis in Social Research, Springer New York, 1985, pp. 137150 .

Hendricks, Lutz, "How Important Is Human Capital for Development? Evidence from Immigrant Earnings," American Economic Review, March 2002, 92 (1), 198-219.

Herrendorf, Berthold and Todd Schoellman, "Why is Measured Productivity so Low in Agriculture?," Working Paper 2011. 
Heston, Alan, Robert Summers, and Bettina Aten, Penn World Table Version 7.0 Center for International Comparisons of Production, Income and Prices at the University of Pennsylvania May 2011.

Hsieh, Chang-Tai and Peter J. Klenow, "Development Accounting," American Economic Journal: Macroeconomics, January 2010, 2 (1), 207-23.

_ and _ , "The Life Cycle of Plants in India and Mexico," Working Paper, Stanford University 2012.

Huggett, Mark, Gustavo Ventura, and Amir Yaron, "Sources of Lifetime Inequality," American Economic Review, 2011, 101 (7), 2923-54.

Hurst, Erik, Geng Li, and Ben Pugsley, "Are Household Surveys Like Tax Forms: Evidence from Income Underreporting of the Self Employed," Review of Economics and Statistics, 2014, 96 (1), 19-33.

Jones, Benjamin F., "The Human Capital Stock: A Generalized Approach," American Economic Review, forthcoming.

Jovanovic, Boyan, "Job Matching and the Theory of Turnover," Journal of Political Economy, October 1979, 87 (5), 972-90.

Kambourov, Gueorgui and Iourii Manovskii, "Accounting for the Changing LifeCycle Profile of Earnings," Working Paper 2009.

King, Miriam, Steven Ruggles, J. Trent Alexander, Sarah Flood, Katie Genadek, Matthew B. Schroeder, Brandon Trampe, and Rebecca Vick, Integrated Public Use Microdata Series, Current Population Survey: Version 3.0. [Machinereadable database], University of Minnesota, 2010.

Klenow, Pete and Andres Rodriguez-Clare, "The Neoclassical Revival in Growth Economics: Has It Gone Too Far?," in "NBER Macroeconomics Annual 1997, Volume 12" NBER Chapters, National Bureau of Economic Research, 1997, pp. 73-114.

Kuruscu, Burhanettin, "Training and Lifetime Income," American Economic Review, June 2006, 96 (3), 832-846.

Lazear, Edward P, "Why Is There Mandatory Retirement?," Journal of Political Economy, December 1979, 87 (6), 1261-84.

Lemieux, Thomas, The "Mincer Equation" Thirty Years After "Schooling, Experience, and Earnings", Springer,

Lucas, Robert E., "Ideas and Growth," Economica, 2009, 76 (301), 1-19.

_ and Benjamin Moll, "Knowledge Growth and the Allocation of Time," NBER Working Papers 17495, National Bureau of Economic Research October 2011.

Manuelli, Rodolfo E. and Ananth Seshadri, "Human Capital and the Wealth of Nations," American Economic Review, 2014, 104 (9), 2736-62.

Michelacci, Claudio and Vincenzo Quadrini, "Financial Markets and Wages," Review of Economic Studies, 04 2009, 76 (2), 795-827. 
Minnesota Population Center, Integrated Public Use Microdata Series, International: Version 6.1 [Machine-readable database], University of Minnesota, 2011.

Murphy, Kevin M and Finis Welch, "Empirical Age-Earnings Profiles," Journal of Labor Economics, April 1990, 8 (2), 202-29.

Perla, Jesse and Christopher Tonetti, "Endogenous Risk and Growth," mimeo, NYU 2011.

Psacharopoulos, George, "Returns to Investment in Education: A Global Update," World Development, 1994, 22 (9), 1325-43.

Schoellman, Todd, "Education Quality and Development Accounting," The Review of Economic Studies, March 2012, 3 (1), 133-175.

Seshadri, Ananth and Nicolas Roys, "The Organisation of Production and Economic Development," Working Paper, University of Wisconsin Madison 2012.

Shastry, Gauri Kartini and David N. Weil, "How Much of Cross-Country Income Variation is Explained By Health?," Journal of the European Economic Association, 04/05 2003, 1 (2-3), 387-396.

Weil, David N., "Accounting for The Effect of Health on Economic Growth," The Quarterly Journal of Economics, 08 2007, 122 (3), 1265-1306. 
Table 1: Returns to Experience and GDP per Capita

\begin{tabular}{|c|c|c|}
\hline & $\begin{array}{c}\text { Corr }\left(\text { Height }_{20}, \text { GDP }\right) \\
(1)\end{array}$ & $\begin{array}{c}\text { Slope }\left(\text { Height }_{20}, \text { GDP }\right) \\
(2)\end{array}$ \\
\hline Benchmark (No cohort or time effects) & $0.60^{* * *}$ & $0.20^{* * *}$ \\
\hline Restriction 1: All growth is due to cohort effects & 0.42 & 0.14 \\
\hline Restriction 2: All growth is due to time effects & $0.58^{* *}$ & $0.13^{* *}$ \\
\hline Restriction 3: Growth is equally due to time and cohort effects & $0.52^{*}$ & $0.13^{*}$ \\
\hline \multicolumn{3}{|c|}{$\begin{array}{l}\text { Notes: Column (1) shows the correlation coefficient between the height of the experience-wage profile at } 20 \\
\text { years of experience and log per capita GDP in } 2010 \text { at PPP. Column }(2) \text { presents the coefficient of from a } \\
\text { bivariate regression. Restrictions } 1,2 \text { and } 3 \text { refer to the estimated returns to potential experience using the } \\
\text { Deaton-Hall method. The sample for the benchmark includes all } 35 \text { countries. The sample for the Deaton- } \\
\text { Hall estimates includes } 12 \text { countries. }{ }^{* * *} \text { and }{ }^{* * *} \text { denote statistical significance at the } 10 \%, 5 \% \text { and } 1 \% \\
\text { levels. }\end{array}$} \\
\hline
\end{tabular}


Table 2: Returns to Experience and GDP per Capita: Alternate Specifications

\begin{tabular}{lcc}
\hline \hline & $\begin{array}{c}\text { Corr }\left(\text { Height }_{20}, \text { GDP }\right) \\
(1)\end{array}$ & $\begin{array}{c}\text { Slope }\left(\text { Height }_{20}, \text { GDP }\right) \\
(2)\end{array}$ \\
\hline Benchmark & $0.60^{* * *}$ & $0.20^{* * *}$ \\
\cline { 2 - 3 } Include Part-Time Workers & $(\mathrm{a})$ Alternative Sample Restrictions \\
\cline { 2 - 3 } Male Workers & $0.51^{* * *}$ & $0.14^{* * *}$ \\
Male Private Workers & $0.54^{* * *}$ & $0.24^{* * *}$ \\
Non-Agricultural Workers & $0.55^{* * *}$ & $0.23^{* * *}$ \\
Older than 18 Years Workers & $0.53^{* * *}$ & $0.18^{* * *}$ \\
Older than 22 Years Workers & $0.59^{* * *}$ & $0.19^{* * *}$ \\
\cline { 2 - 3 } & $0.43^{* *}$ & $0.15^{* *}$ \\
\cline { 2 - 3 } Start Work at Age 6 & (b) Alternative Definitions of Potential Experience \\
Start Work at Age 15 & $0.50^{* * *}$ & $0.17^{* * *}$ \\
\hline
\end{tabular}

Notes: Column (1) shows the correlation coefficient between the height of the experiencewage profile at 20 years of experience and log per capita GDP in 2010 at PPP. Column (2) presents the coefficient of from a bivariate regression. The sample for the benchmark includes all 35 countries. ${ }^{*}, * *$ and ${ }^{* * *}$ denote statistical significance at the $10 \%, 5 \%$ and $1 \%$ levels. 
Table 3: Variance of Human Capital Stocks Across Countries

\begin{tabular}{|c|c|c|}
\hline & $\operatorname{Var}(\log (\mathrm{H}))$ & Slope $(\log (\mathrm{H}), \log (\mathrm{GDP}))$ \\
\hline Human Capital Measure & (1) & $(2)$ \\
\hline & \multicolumn{2}{|c|}{ (a) Benchmark } \\
\hline Schooling & 0.12 & 0.15 \\
\hline Experience & 0.09 & 0.21 \\
\hline \multirow[t]{2}{*}{ Schooling + Experience } & 0.26 & 0.36 \\
\hline & \multicolumn{2}{|c|}{ (b) Restriction 1: All Growth is due to Cohort Effects } \\
\hline Schooling & 0.11 & 0.11 \\
\hline Experience & 0.14 & 0.04 \\
\hline \multirow[t]{2}{*}{ Schooling + Experience } & 0.40 & 0.16 \\
\hline & \multicolumn{2}{|c|}{ (c) Restriction 2: All Growth is due to Time Effects } \\
\hline Schooling & 0.07 & 0.17 \\
\hline Experience & 0.07 & 0.18 \\
\hline \multirow[t]{2}{*}{ Schooling + Experience } & 0.17 & 0.35 \\
\hline & \multicolumn{2}{|c|}{ (d) Restriction 3: Growth is Equally due to Cohort and Time Effects } \\
\hline Schooling & 0.08 & 0.14 \\
\hline Experience & 0.08 & 0.11 \\
\hline Schooling + Experience & 0.24 & 0.25 \\
\hline
\end{tabular}

Notes: Column (1) presents the cross-country variance in human capital stocks that take into account human capital from schooling, experience and experience + schooling. Column (2) presents the coefficient of the bivariate regression between the log of human capital and the log of 2010 GDP per capita at PPP. In Panels (b)-(d), restrictions 1, 2 and 3 refer to the estimated returns to potential experience using the Deaton-Hall method in countries with multiple cross-sections of data spanning fifteen or more years. The sample in Panel (a) includes 35 countries. The samples used in Panels (b) (d) include 12 countries. 
Table 4: Development Accounting

\begin{tabular}{|c|c|c|}
\hline Human Capital Measure & $\begin{array}{c}\text { Success }_{1} \\
(1) \\
\end{array}$ & $\begin{array}{c}\text { Slope }\left(\log \left(\mathrm{Y}_{\mathrm{KH}}\right), \log (\mathrm{GDP})\right) \\
(2)\end{array}$ \\
\hline & \multicolumn{2}{|c|}{ (a) Benchmark } \\
\hline Schooling & 0.40 & 0.53 \\
\hline Experience & 0.40 & 0.56 \\
\hline \multirow[t]{2}{*}{ Schooling + Experience } & 0.63 & 0.65 \\
\hline & \multicolumn{2}{|c|}{ (b) Restriction 1: All Growth is due to Cohort Effects } \\
\hline Schooling & 0.33 & 0.51 \\
\hline Experience & 0.28 & 0.43 \\
\hline \multirow[t]{2}{*}{ Schooling + Experience } & 0.51 & 0.52 \\
\hline & \multicolumn{2}{|c|}{ (c) Restriction 2: All Growth is due to Time Effects } \\
\hline Schooling & 0.34 & 0.56 \\
\hline Experience & 0.31 & 0.53 \\
\hline \multirow[t]{2}{*}{ Schooling + Experience } & 0.49 & 0.66 \\
\hline & \multicolumn{2}{|c|}{ (d) Restriction 3: Growth is Equally due to Cohort and Time Effects } \\
\hline Schooling & 0.33 & 0.53 \\
\hline Experience & 0.28 & 0.48 \\
\hline Schooling + Experience & 0.47 & 0.59 \\
\hline
\end{tabular}

Notes: Column (1) presents the cross-country variance of $\log \mathrm{Y}_{\mathrm{KH}}$ (from from schooling, experience and experience + schooling) divided by the cross-country variance in of log per capita 2010 GDP. $\mathrm{Y}_{\mathrm{KH}}$ is output per worker assuming that countries differ only in their stocks of human and physical capital per worker. Column (2) presents the coefficient from a bivariate regression. In Panel (a), the sample includes 35 countries. In Panels (b)-(d), restrictions 1, 2 and 3 refer to the estimated returns to potential experience using the Deaton-Hall method. The samples include 12 countries. 
Figure 1: Fully Flexible Experience-Wage Profiles - India, Mexico and the United States

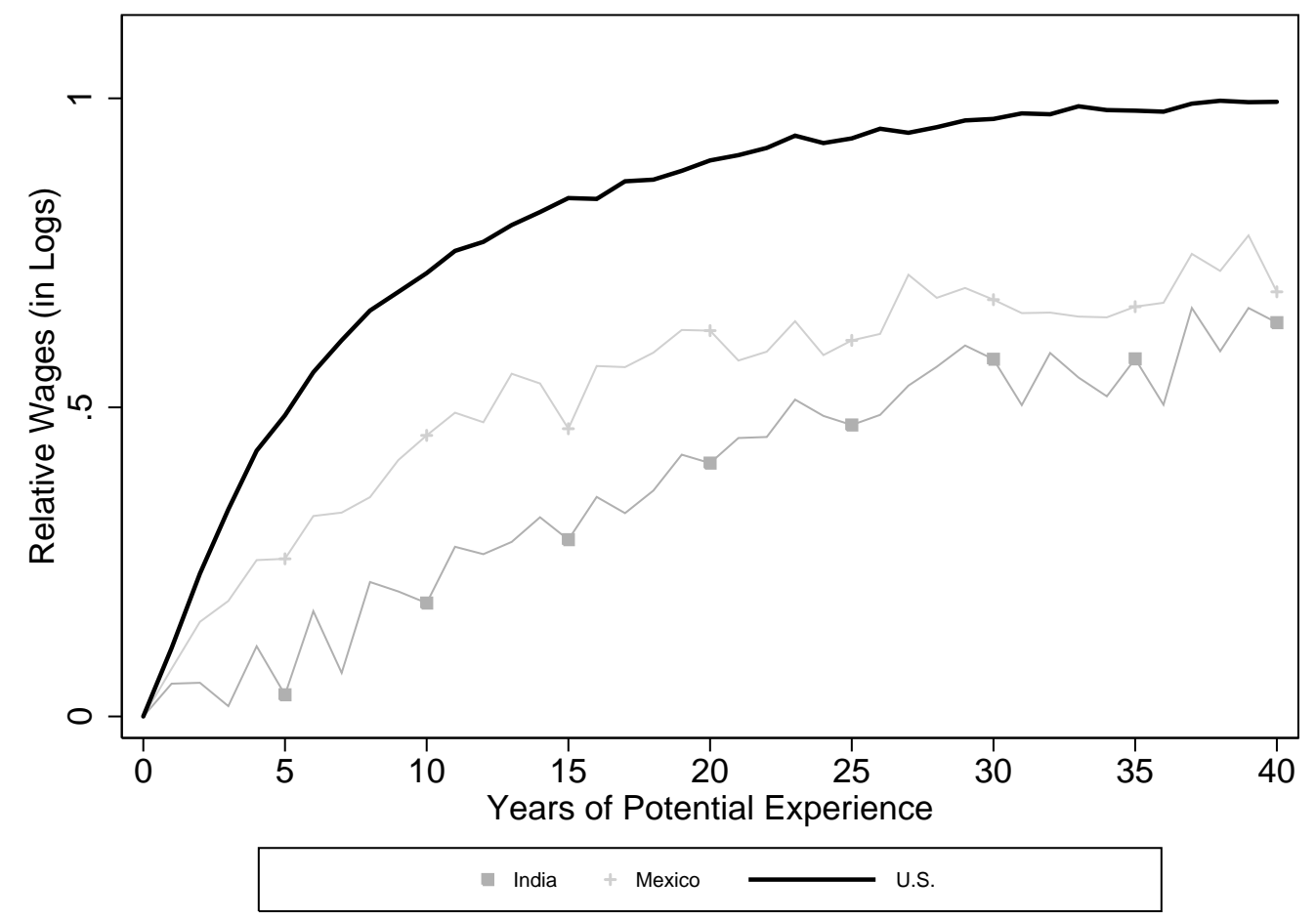

Figure 2: Returns to Experience vs. GDP per Capita - All Countries

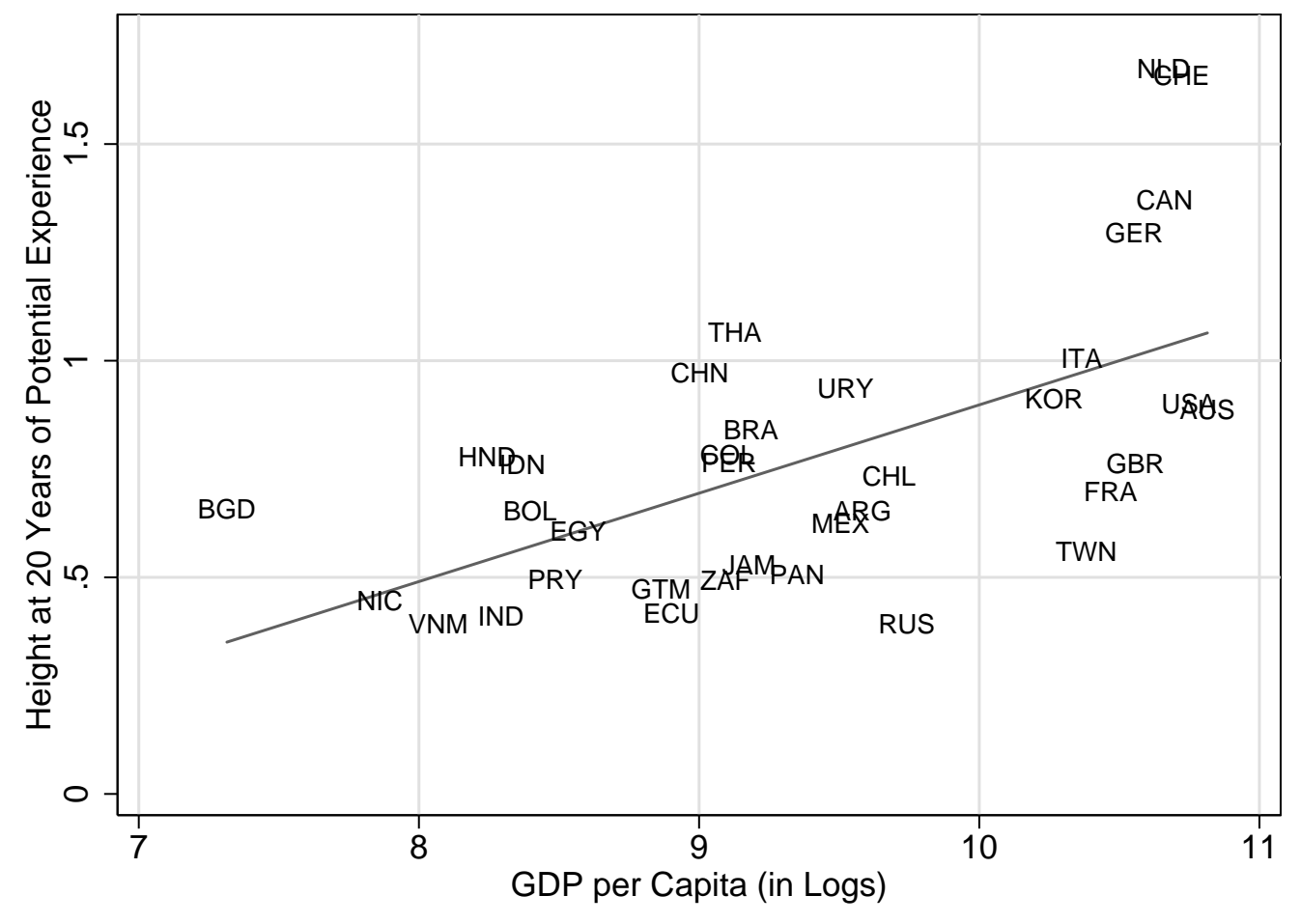


Figure 3: Returns to Experience vs. GDP per Capita - Restriction 1: All Growth is due to Cohort Effects

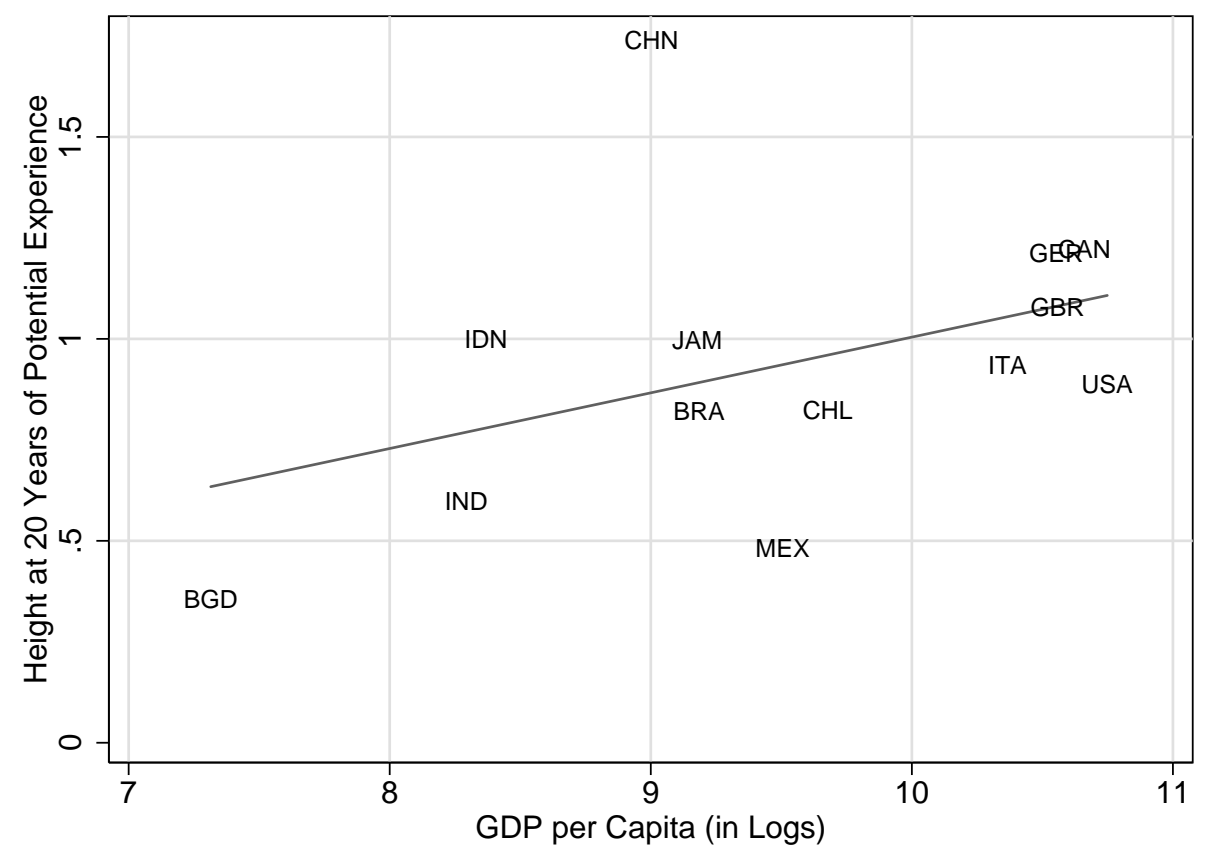

Figure 4: Returns to Experience vs GDP per Capita -Restriction 2: All Growth is due to Time Effects

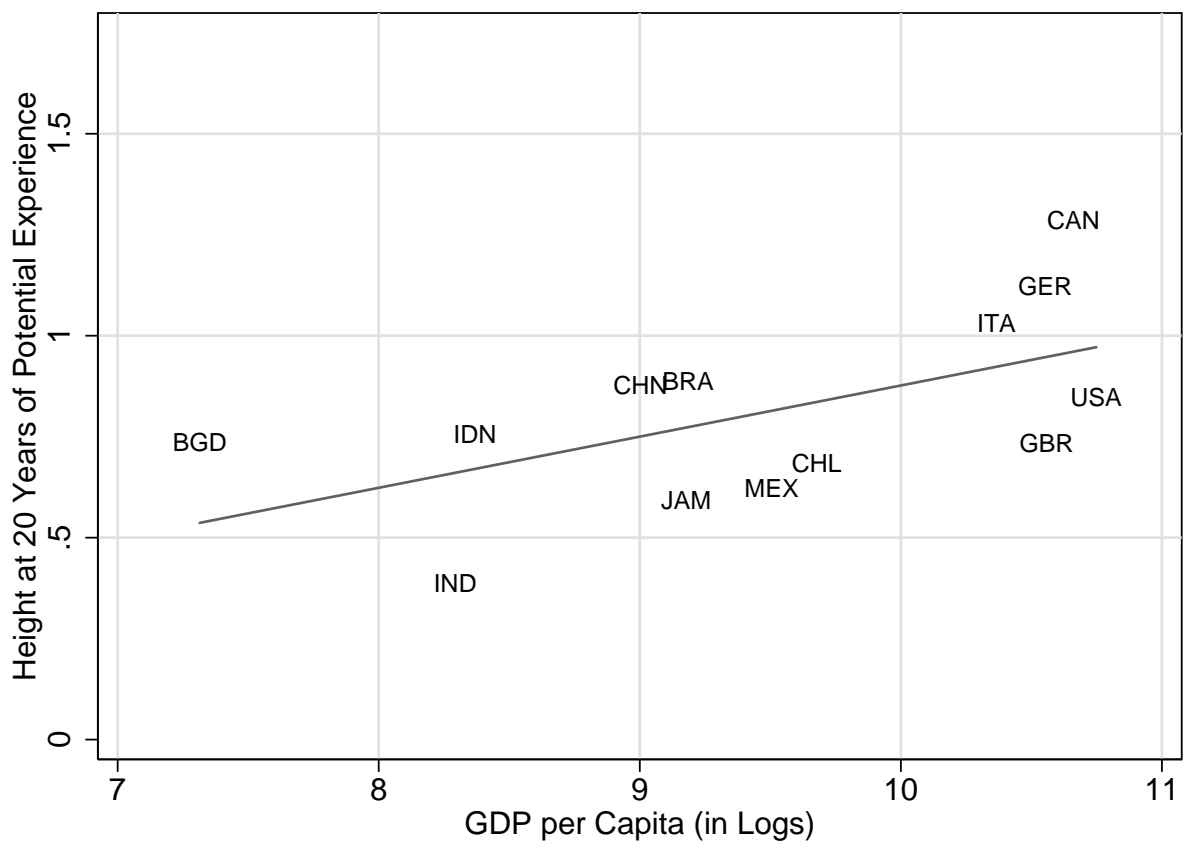


Figure 5: Returns to Experience vs. GDP per Capita - Restriction 3: Growth is equally due to Cohort and Time Effects

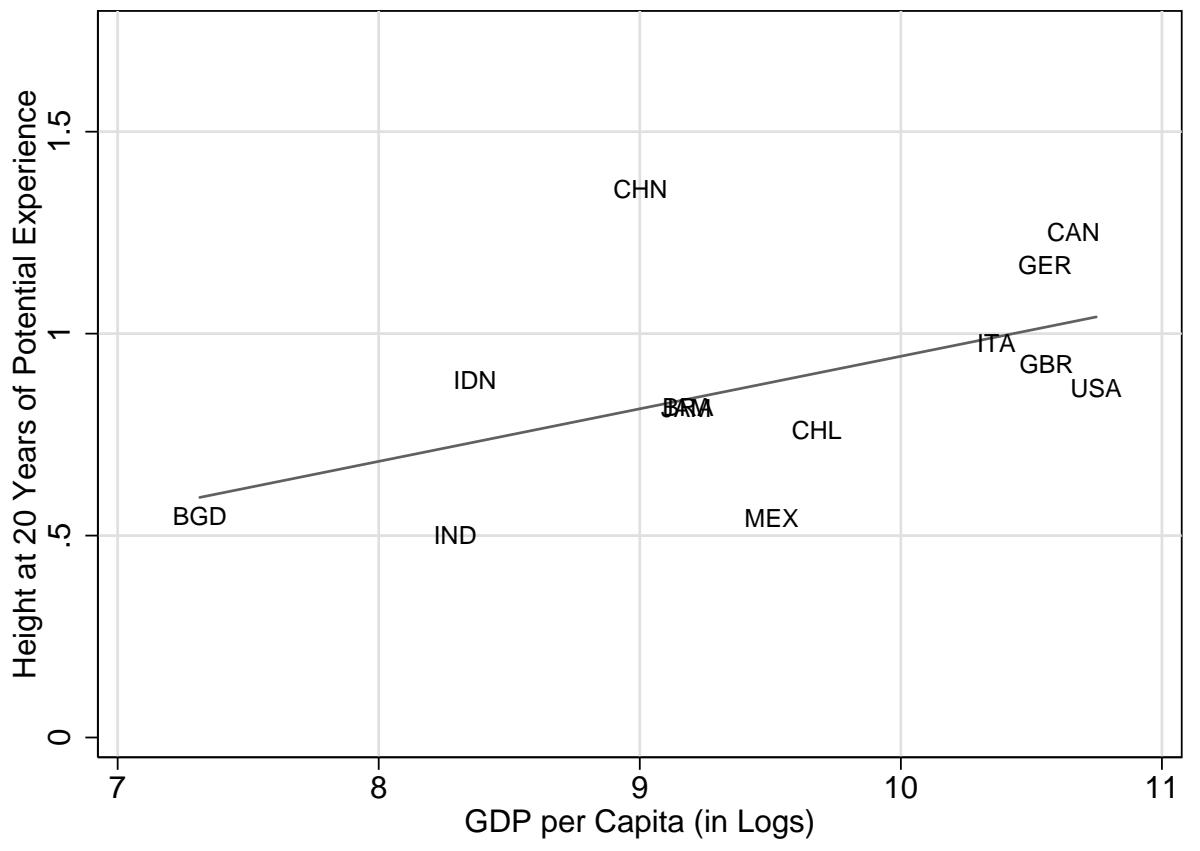

Figure 6: Returns to Experience Among New Immigrants

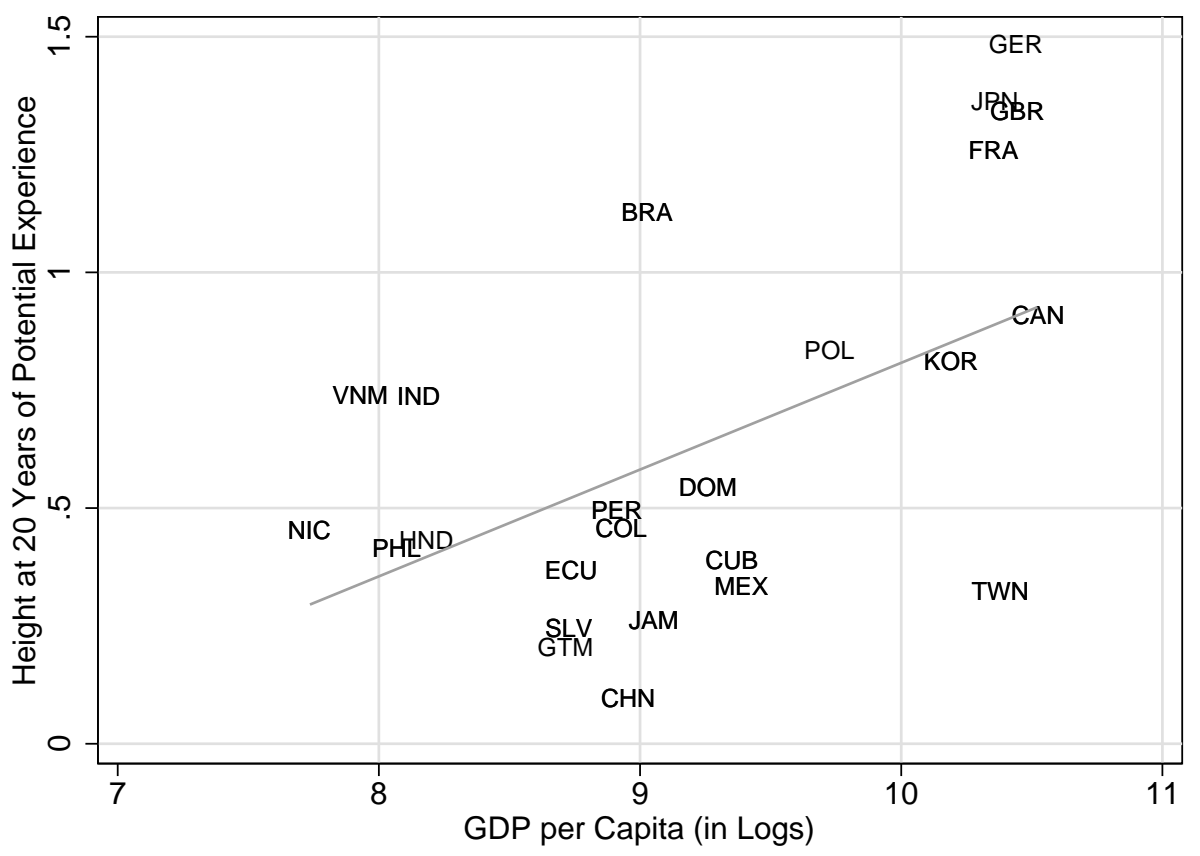


Figure 7: Returns to Experience for All Immigrants

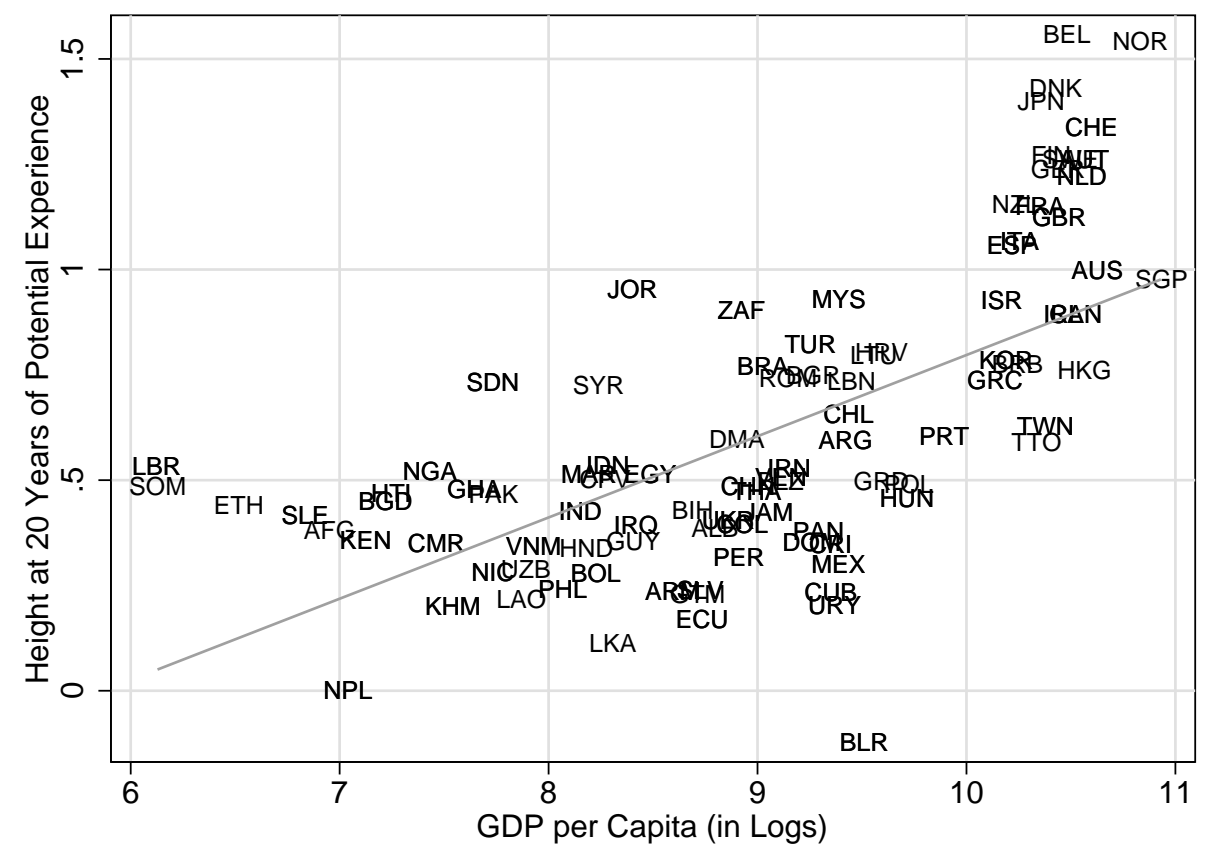

Figure 8: Returns to Experience for Immigrants and Stayers

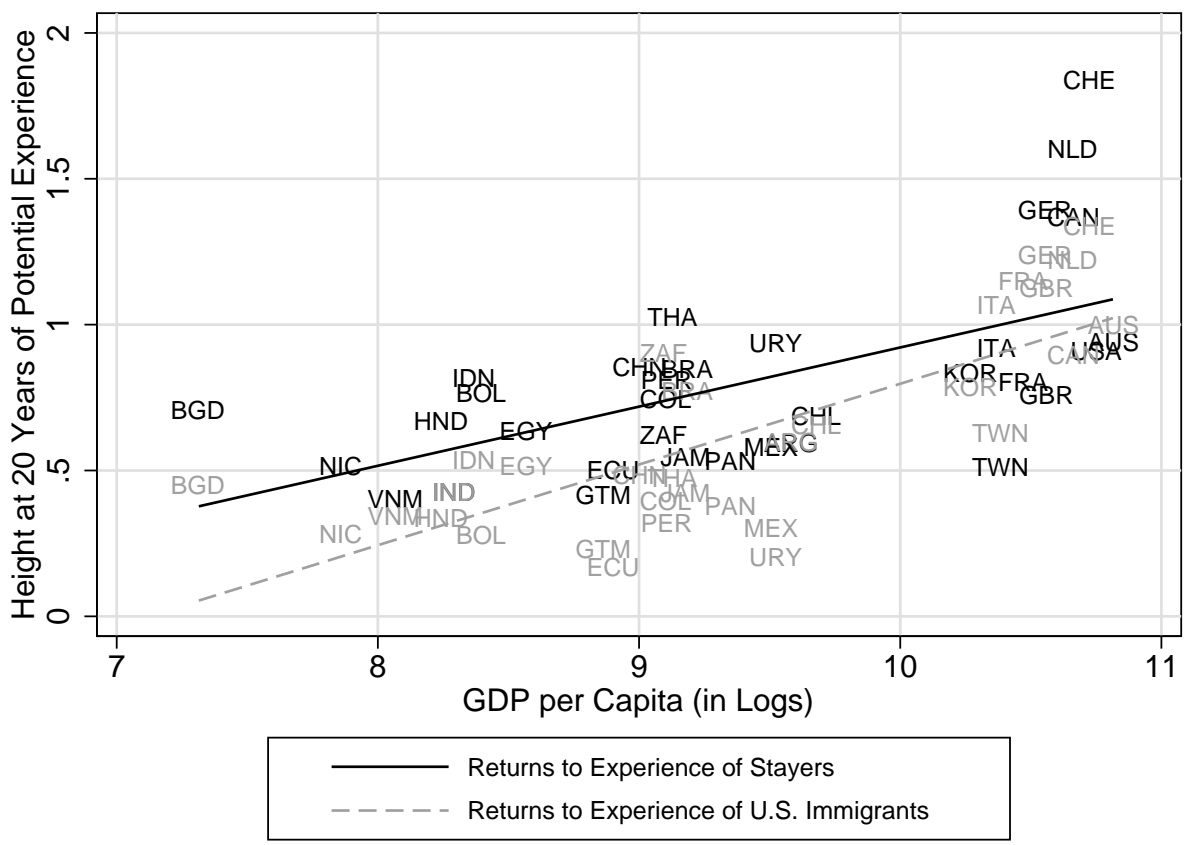


Figure 9: Average Years of Schooling for Immigrants and Stayers
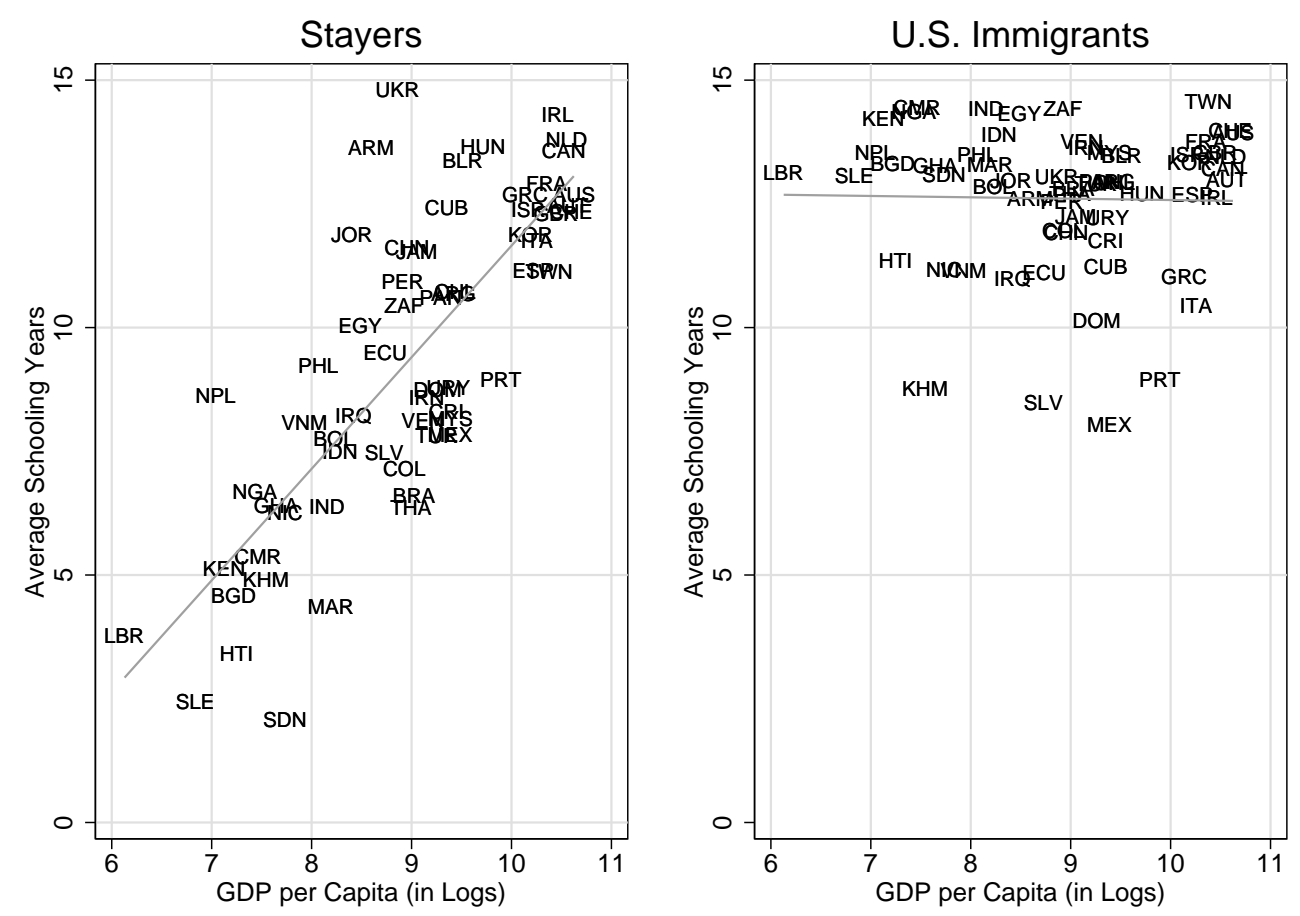

Figure 10: Fraction of College Educated Workers in High-Skilled Occupations for Immigrants and Stayers
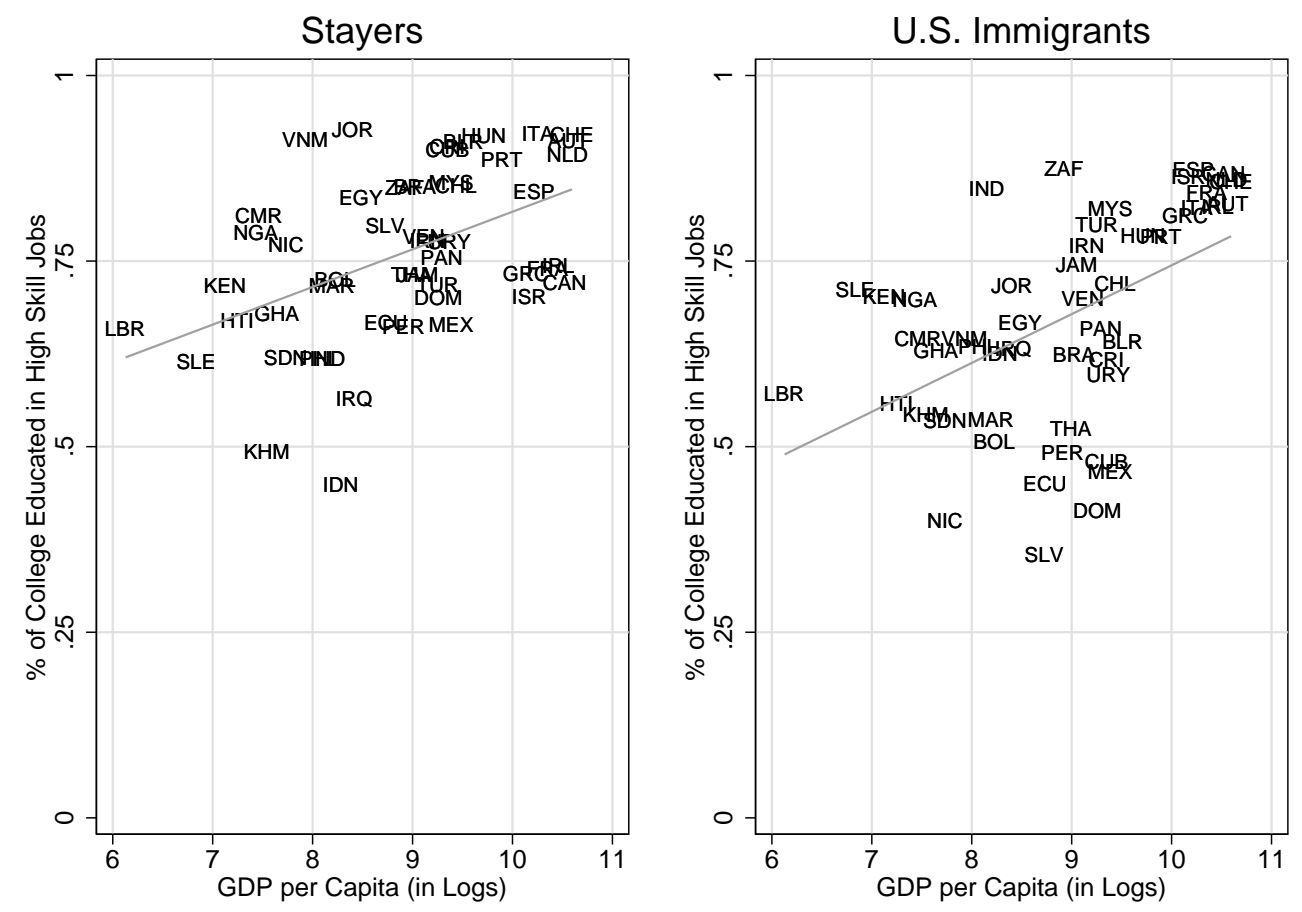

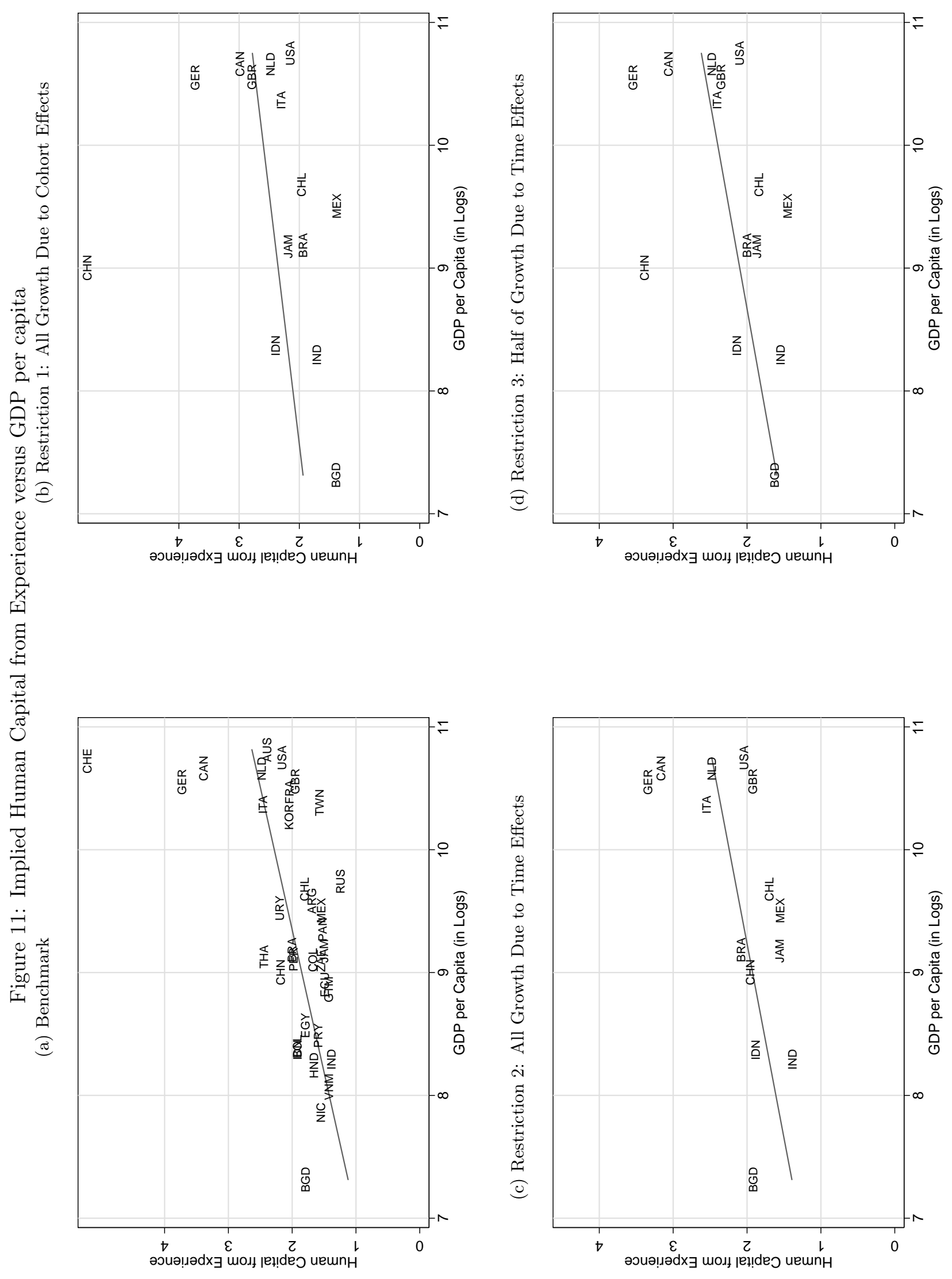


\section{A Online Appendix - Not for Publication}

\section{A.1 Data Sources}

The surveys we employ in our analysis are listed below for each country. All surveys are nationally representative unless noted. We attempted to obtain data for every country in the world with a population greater than one million people. We obtained a number of surveys from the Food and Agriculture Organization's (FAO) Rural Income Generating Activity (RIGA) database; these surveys are available here: www.fao.org/economic/riga/rigadatabase/en/. We obtained a number of other surveys through the Integrated Public Use Microdata Series (IPUMS) (Minnesota Population Center, 2011; King et al., 2010), which can be found here: www.ipums.org. The remaining surveys were made available to us by the statistical agencies of the countries in question or other sources, as listed below.

- Argentina: Encuesta Permanente de Hogares, 2003, 2007 and 2010, from the Instituto Nacional de Estadística y Censos; representative of urban areas.

- Australia: Household Income and Labour Dynamics in Australia, yearly from 2001 to 2009, from the Australian Department of Families, Housing, Community Services and Indigenous Affairs, available from the Cornell Department of Policy Analysis and Management.

- Bangladesh: Household Income and Expenditure Survey, 1995, 2000, 2005 and 2010, from the Bangladesh Bureau of Statistics, available from the FAO RIGA database.

- Bolivia: Encuesta de Hogares, 2005, from the Bolivian Instituto Nacional de Estadística.

- Brazil: Recenseamento Geral do Brasil, Censo Demográfico, 1970 (5\% sample), 1980 (5\% sample), 1991 (5.8\% sample), and 2000 (6\% sample), from the Instituto Brasileiro de Geografia e Estatística (IBGE), available from IPUMS, and Pesquisa Nacional por Amostra de Domicilios, yearly from 2001 to 2010, from IBGE.

- Canada: Census of Canada, 1971 (1\% Sample), 1981 (2\% Sample), 1991 (3\% Sample) and 2001 (2.7\% Sample), available from IPUMS.

- Chile: National Socioeconomic Characterization Survey (CASEN), 1992, 1994, 1996, 1998, 2000, 2003, 2006 and 2009, from the Chilean Ministry of Planning and Cooperation.

- China: Urban Household Surveys (0.01\% of urban households, 27 cities), 1988 to 2005 yearly; representative of urban areas.

- Colombia: XIV National Population and III Housing Census by Departmento Administrativo Nacional de Estadística (DANE), 1973 (10\% of households), available from IPUMS.

- Ecuador: Estudio de Condiciones de Vida, 1995, from the Instituto Nacional de Estadística y Censos, available from the FAO RIGA database. 
- Egypt: Labor Market Panel Survey, 2006 from the Egyptian Central Agency for Public Mobilization and Statistics.

- France: Enquete Emploi, yearly from 1993 to 2001, from the Ministre de l'Économie de l'Industrie et de l'Emploi.

- Germany: German Socioeconomic Panel (SOEP), yearly from 1991 to 2009, from the German Institute for Economic Research (DIW Berlin).

- Guatemala: Encuesta Nacional de Condiciones de Vida, 2000 and 2006, from the Instituto Nacional de Estadistica.

- Honduras: Encuesta Permanente de Hogares de Propósitos Multiples, 2005, from the Secretaria de Trabajo y Seguridad Social.

- India: Socio Economic Survey by National Sample Survey Organization, 1983, 1987, 1993, 1999 and 2004, available from IPUMS.

- Indonesia: Family Life Survey, National Labour Force Survey (SAKERNAS), 1988 to 1994 and 1996 to 2011, from the Indonesia Badan Pusat Statistik

- Italy: Survey on Household Income and Wealth, 1991, 1993, 1995, 1998, 2000, 2002, 2004, 2006, 2008, 2010, from the Bank of Italy.

- Jamaica: Population Census, 1982, 1991 and 2001, (10\% samples) from the Statistical Institute of Jamaica, available from IPUMS.

- Mexico: XI General Population and Housing Census, 1990 (10\% sample); Population and Dwelling Count, 1995 (0.4\% of sample); XII General Population and Housing Census, 2000 (10.6\% of sample), available from IPUMS.

- Netherlands: DNB Household Survey, yearly from 1994 to 2010, available from centERdata.

- Nicaragua: Encuesta Nacional de Hogares sobre Medición de Nivel de Vida, 1998 and 2001, from the Instituto Nacional de Estadística y Censos, available from the FAO RIGA database.

- Panama: Censo Nacional de Población y de Vivienda de Panamá, 1990 (10\% sample), available from IPUMS, and the Encuesta de Condiciones de Vida, 2003, from the Dirección de Estadística y Censos de Panamá, available from the FAO RIGA database.

- Paraguay: Encuesta Permanente de Hogares, 2011, from the Direccion General de Estadistica.

- Peru: Encuesta Nacional de Hogares, 2004 and 2010, from the from the Instituto Nacional de Estadística y Informática.

- Russia: Russia Longitudinal Monitoring Survey, yearly from 2000 to 2010, available from the Carolina Population Center at the University of North Carolina, Chapel Hill.

- South Africa: Labor Force Survey, 2000, 2001 and 2002 from Statistics South Africa. 
- South Korea: Korea Labor and Income Panel Study, yearly from 1999 to 2008, from the Korea Labor Institute, available from the Cornell Department of Policy Analysis and Management.

- Switzerland: Swiss Household Panel, yearly from 1999 to 2009, from the Swiss Foundation for Research in Social Sciences, available from the Cornell Department of Policy Analysis and Management.

- Taiwan: Survey of Family Income and Expenditure, yearly from 1995 to 2003, available from the Research Program in Development Studies at Princeton University.

- Thailand: Thailand Socioeconomic Survey, 1990, 1992, 1994, 1996, 1998 and 1999, available from the Research Program in Development Studies at Princeton University.

- United Kingdom: British Household Panel Survey, yearly from 1992 to 2009, from the Institute for Social \& Economic Research at the University of Essex.

- United States: Census of Population and Housing, 1960 (1\% Sample), 1970 (1\% Sample), 1980 (5\% Sample), 1990 (5\% Sample) , 2000 (5\% Sample); American Community Survey, 2005 (1\% Sample); Current Population Survey, yearly from 1980 to 2010; all available from IPUMS.

- Uruguay: Extended National Survey of Households, 2006, from the Uruguay National Institute of Statistics, available from IPUMS.

- Vietnam: Living Standards Survey, 1998 and Household Living Standards Survey, 2002, both from the General Statistics Office of Vietnam, available from the FAO RIGA.

All calculations in our analysis are weighted using the applicable sample weights for each survey. We express all earnings and wage data in local currency units of the most recent year in the data using the consumer price index of the country in question, taken from the IMF's International Financial Statistics database. In each survey, we drop the top and bottom $1 \%$ of earners to remove potential outliers, and to minimize the impact of potential cross-country differences in top-coding procedures.

For most countries, we measure hours as the actual hours worked in the past week (or in some recent reference week.) For the United States, Brazil (the census data) and Italy, we measure hours as the usual weekly hours worked (which is what is available). For Colombia, China, India, Panama (the census data), Taiwan and Thailand, we have no hours data available, and impute hours as the average hours worked in all other countries for the individual's level of experience. We define an individual to be a full-time worker if she works more than 30 hours per week. As noticed, for few countries, namely China, Colombia, India, Panama, and Thailand, we do not have hours data. For India, the data report whether an individual is a full-time worker. We use this variable to restrict the sample. For China, Colombia, Panama, and Thailand we have instead no information and hence we are forced to keep all the workers. In order to be sure that the inclusion of these countries is not driving our result, we recomputed all the analysis of the paper excluding them. All the results are robust to this exclusion and are available upon request

For most countries, labor earnings and hours worked are for both primary and secondary jobs. In Argentina, Chile, France, South Korea and Uruguay, labor earnings and hours 
worked are for just the primary job. For Brazil (the census data) and Switzerland, we measure labor income as the total income earned of individuals reporting to be primarily wage earners (as opposed to self-employed.) In most countries, earnings are reported at the monthly frequencies. The exceptions are Australia, Canada, Germany, Jamaica, South Korea, and the United States, in which earnings are measured at the annual frequency, and India, in which earnings are measured at the weekly frequency. In all surveys, earnings are before taxes. The numbers for per capita GDP at PPP that we use in some of our calculations and figures are taken from the Penn World Tables (Heston et al., 2011).

When we use repeated cross sections in the paper to estimate experience-wage profiles, we draw on data for all countries for which we have cross-sections spanning 15 years. These countries are: Bangladesh (1995, 2000, 2005 and 2010), Brazil (1970, 1980, 1991, 2000-2010), Canada (1971, 1981, 1991, 2001), Chile (1990, 1992, 1994, 1996, 1998, 2000, 2003, 2006, 2009), China (1988 - 2005), Germany (1991 - 2009), India (1983, 1987, 1993, 1999, 2004), Indonesia (1988-1994, 1996-2011), Italy (1991, 1993, 1995, 1998, 2000, 2002, 2004, 2006, 2008, 2010), Jamaica (1982, 1991, 2001), Mexico (1970, 1980, 1990, 1995, 2000, 2005), United Kingdom (1992 - 2009), United States (1960, 1970, 1980, 2000, 2005).

\section{A.2 Restrictions for Identification of Cohort and Time Effects}

This section adds some additional structure to our conceptual framework in Section 3.1 that gives more precise interpretations to cohort and time effects, and then uses it to derive meaningful restrictions on cohort and time effects that can be used to separately identify them using the Deaton-Hall method.

A Framework for Thinking about Cohort and Time Effects. Section 3.1 motivated our main estimating equation (4) from a simple model of human capital but left unspecified why the skill price $\omega_{c t}$ is cohort- and time-specific. Here, we provide a simple model that fills this gap and is also consistent with the development accounting exercise in Section 6. There is a representative firm with a constant returns production function

$$
Y_{t}=F\left(K_{t}, Z_{t} \sum_{c \in C_{t}} X_{c} H_{c t}\right),
$$

where $Y_{t}$ denotes output, $K_{t}$ capital, and $C_{t}$ the set of cohorts working at time $t . H_{c t}=$ $\sum_{i=1}^{N_{c t}} h_{i c t}$ is the aggregate human capital of cohort $c$ at time $t$ and its efficiency depends on two factors: cohort-neutral efficiency $Z_{t}$, and cohort-specific efficiency $X_{c}$. This production function can be usefully written as

$$
Y_{t}=F\left(K_{t}, A_{t} H_{t}\right)
$$

where $H_{t}=\sum_{c \in C_{t}} H_{c t}$ is the aggregate human capital stock in year $t$ and the efficiency of aggregate human capital $A_{t}$ has two determinants $A_{t}=Z_{t} \bar{X}_{t}$ where

$$
\bar{X}_{t} \equiv \sum_{c \in C_{t}} X_{c} \frac{H_{c t}}{H_{t}}
$$

Note that $A_{t}$ is what the development accounting literature refers to as TFP. Aggregate human capital efficiency, $A_{t}$, can improve over time for two reasons: $i$ ) directly, due to 
increases in cohort-neutral human capital efficiency; and ii) indirectly, due to changes in the composition of cohorts active in the labor market. For example, suppose that young cohorts are more productive than old ones. Then human capital efficiency will improve over time as old cohorts exit the labor force and young cohorts enter.

From the profit maximization problem of firms, we can now derive an expression for the skill price $\omega_{c t}$ in terms of the primitives of this simple model:

$$
\omega_{c t}=\frac{\partial Y_{t}}{\partial H_{c t}}=F_{L}\left(\kappa_{t}, 1\right) Z_{t} X_{c}
$$

where $\kappa_{t} \equiv K_{t} /\left(A_{t} H_{t}\right)$ is capital per units of "effective human capital". On a balanced growth path, $\kappa_{t}$ would equal a constant. As in equation (3) this can be written as $\omega_{c t}=$ $\bar{\omega} \exp \left(\gamma_{t}+\chi_{c}\right)$ where the cohort and time effects are given by

$$
\bar{\omega} \exp \left(\gamma_{t}\right) \equiv F_{L}\left(\kappa_{t}, 1\right) Z_{t}, \quad \exp \left(\chi_{c}\right) \equiv X_{c}
$$

The time effect $\gamma_{t}$ captures changes in cohort-neutral productivity $Z_{t}$ and capital accumulation $\kappa_{t}$, and the cohort effect $\chi_{c}$ captures changes in cohort-specific productivity $X_{c}$.

Restrictions on Cohort and Time Effects. To impose meaningful restrictions on cohort and time effects, consider the evolution of aggregate labor productivity (or more precisely "aggregate human capital productivity")

$$
\mathrm{MPH}_{t}=F_{L}\left(\kappa_{t}, 1\right) A_{t}=F_{L}\left(\kappa_{t}, 1\right) Z_{t} \bar{X}_{t} .
$$

First, note that on a balanced growth path, with $\kappa_{t}$ constant, the growth rate of labor productivity $\mathrm{MPH}_{t}$ would simply equal that of aggregate labor efficiency $A_{t}$. Not surprisingly then given our discussion above, labor productivity growth can also be decomposed into a part "due to time effects", i.e. economy-wide changes affecting everyone, and a part "due to cohort effects", i.e. improvements specific to individual cohorts. To see this use (23) to write

$$
\mathrm{MPH}_{t}=\bar{\omega} \exp \left(\gamma_{t}+\bar{\chi}_{t}\right),
$$

where $\bar{\chi}_{t} \equiv \log \bar{X}_{t}$. Equation (25) is the key equation we use to derive meaningful restrictions on cohort and time effects. The basic idea is to decompose the time series for $\mathrm{MPH}_{t}$ into a trend component and a cyclical component and to make assumptions on whether the trend component ("labor productivity growth") is attributed to time or to cohort effects.

In practice, this is executed in the following way. First, it is convenient to define time periods in deviations from the sample mean, i.e. such that $\frac{1}{T} \sum_{t=0}^{T} t=0$, and similarly renormalize $\gamma_{t}$ and $\bar{\chi}_{t}$ such that $\frac{1}{T} \sum_{t=0}^{T} \gamma_{t}=\frac{1}{T} \sum_{t=0}^{T} \bar{\chi}_{t}=0$ (an appropriate choice of the constant $\bar{\omega}$ does the trick). Second, the series for $\gamma_{t}$ and $\bar{\chi}_{t}$ can be decomposed into a trend component and a cyclical component

$$
\gamma_{t}=g_{\gamma} t+u_{\gamma, t}, \quad \bar{\chi}_{t}=g_{\chi} t+u_{\chi, t},
$$

where

$$
g_{\gamma}=\frac{\sum_{t=0}^{T} \gamma_{t} t}{\sum_{t=0}^{T} t^{2}}, \quad g_{\chi}=\frac{\sum_{t=0}^{T} \bar{\chi}_{t} t}{\sum_{t=0}^{T} t^{2}} .
$$

Intuitively, one simply runs a regression of $\gamma_{t}$ and $\chi_{t}$ on time, thereby decomposing each 
time series into a trend component and a component that is orthogonal to the time trend. Finally, from (25), aggregate labor productivity is

$$
\log \mathrm{MPH}_{t}=\log \bar{\omega}+g_{M} t+u_{M, t},
$$

where $g_{M}=g_{\gamma}+g_{\chi}$ and $u_{M, t}=u_{\gamma, t}+u_{\chi, t}$. The different restrictions we use are then simply different ways of splitting $g_{M}$ between $g_{\gamma}$ and $g_{\chi}$. The three restrictions for which we present results in the main text are as follows.

Restriction 1: the time trend in labor productivity growth is entirely due to cohort effects:

$$
g_{M}=g_{\chi}, \quad g_{\gamma}=0 .
$$

From (26) this implies the linear restriction $\sum_{t=0}^{T} \gamma_{t} t=0$, i.e. that time effects are orthogonal to a time trend and capture only cyclical variation. This is exactly the same restriction as equation (2.94) in Deaton (1997).

Restriction 2: the time trend in labor productivity growth is entirely due to year effects:

$$
g_{M}=g_{\gamma}, \quad g_{\chi}=0 .
$$

From (26) this implies the linear restriction $\sum_{t=0}^{T} \bar{\chi}_{t} t=0$ or

$$
\sum_{t=0}^{T} \log \left(\sum_{c \in C_{t}} \exp \left(\chi_{c}\right) \frac{H_{c t}}{H_{t}}\right) t=0 .
$$

Note that the human capital stocks $H_{c t}$ enter this restriction. Since the construction of human capital stocks requires estimating equation (4), it is necessary to use an iterative procedure.

Restriction 3: a share $\theta$ of the time trend in labor productivity growth is due to year effects:

$$
g_{\gamma}=\theta g_{M}, \quad g_{\chi}=(1-\theta) g_{M} .
$$

From (26), this implies the linear restriction

$$
\theta \sum_{t=0}^{T} \bar{\chi}_{t} t=(1-\theta) \sum_{t=0}^{T} \gamma_{t} t .
$$

It can be seen that restrictions 1 and 2 are the special cases $\theta=0$ and $\theta=1$. In the main text, we represent results for the case $\theta=1 / 2$.

\section{Understanding Cohort and Time Controls: The Case of China}

To illustrate how our controls for cohort and time effects work in practice, we consider the case of China in detail. Figure A.6 plots the estimated effects of experience, cohort and time in China under Restriction 1. In this restriction, all labor productivity growth is due to cohort effects, while time effects capture cyclical influences. The upper left panel reproduces the cross-sectional returns to experience (i.e., no controls for either time or cohort) for convenience. The bottom panels show the estimated cohort effects and time effects. The upper right panel shows the experience-wage profile after controls for cohort and time.

Figure A.6 shows that the experience-wage profile for China is much steeper under Restriction 1 than in the cross-sectional estimate. To see why, note that cohort effects 
are steeply upward sloping (bottom left panel), meaning that younger cohorts are much more productive than older cohorts. How then can one reconcile higher wages for more experienced workers in the cross section (upper left panel) than less experienced workers? The answer is that the return to experience must be very high (upper right panel).

Figure A.7 plots the estimated effects of experience, cohort and time in China under Restriction 2. In this restriction, all labor productivity growth is due to time effects, while cohort effects have no time trend. Here, the experience-wage profiles are very similar when controlling for cohort and time effects as in the cross-sectional estimates (upper two panels). The reason is that when all productivity growth is due to time effects, cohort effects have no overall trend. Thus, this restriction implies that older and younger cohorts have similar producitivity levels. It follows that controlling for cohort effects does little to estimated experience-wage profiles.

\section{A.3 Composition Effects}

Agriculture. A key difference between rich and poor countries is that poor countries tend to have a much larger share of workers that engage in agriculture than rich countries. This could affect our estimates of average experience-wage profiles for each country if profiles are flatter for agricultural workers, which has been found to be true in the United States (Herrendorf and Schoellman, 2011).

To consider the role of this compositional difference, we estimate equation (4) separately for the agricultural and non-agricultural sectors. The experience-wage profile of country $j$ is then simply a weighted average of the sectoral profiles

$$
f_{j}(x)=\ell_{A, j}(x) f_{A, j}(x)+\left(1-\ell_{A, j}(x)\right) f_{N, j}(x),
$$

where $\ell_{A, j}(x)$ is the employment share in agriculture in country $j$ and $A$ stands for agrsculture and $N$ for non-agriculture. ${ }^{29}$ Figure A.1a shows the height of the experience-wage profile at twenty years of experience in agriculture plotted against that in non-agriculture. It can be seen that all but a few countries lie below the 45-degree line. In other words, for all but a few countries the experience-wage profiles in agriculture are flatter than those in non-agriculture, though only modestly so.

To assess the quantitative importance of the cross-country differences in the proportions of workers engaged in agriculture for the differences in experience-wage profiles, we conduct the following counterfactual exercise: we ask what would a country's experience-wage profile look like if that country had the United States' employment share in agriculture. We compute the following counterfactual experience-wage profiles for each country $j$

$$
\tilde{f}_{j}(x)=\ell_{A, U S}(x) f_{A, j}(x)+\left(1-\ell_{A, U S}(x)\right) f_{N, j}(x) .
$$

If all of the cross-country differences in experience-wage profiles were due to sectoral differences, then this counterfactual would eliminate all such differences. Figure A.1b graphs the height of both the actual and counterfactual profiles at twenty years of experience against per capita GDP (using the countries for which data allow us to identify a worker's sector). If composition effects explained all cross-country differences in the returns to experience, the counterfactual heights for all countries would lie on a straight horizontal line

\footnotetext{
${ }^{29}$ To see this, note that by the law of iterated expectations, the projection of wages on experience, $x$, and schooling, $s$, can be decomposed by sector, $z$, as $E[\log (w) \mid x, s]=\operatorname{Pr}(z=A \mid s, x) E[\log (w) \mid x, s, z=$ $A]+\operatorname{Pr}(z=N \mid s, x) E[\log (w) \mid x, s, z=N]$.
} 
at the level of the United States. Instead, the counterfactual profiles are very similar to the actual ones. We calculate a slope coefficient of 0.19 in the counterfactual, compared to 0.22 in the actual data. In other words, differences in employment shares between agriculture and non-agriculture explain a very small part of the cross-country differences in experience-wage profiles.

Schooling. Another important compositional difference between rich and poor countries is that workers in poor countries attain fewer years of schooling on average, which could drive our cross-country results if more educated workers have steeper experience-wage profiles than less educated ones. Several studies have pointed out that more educated workers have steeper age-wage profiles (see, for example, Carroll and Summers (1991), Kambourov and Manovskii (2009) and Guvenen (2007)).

We explore the extent to which this difference drives our results by allowing the returns to experience to vary by the different levels of schooling in the human capital production function in equation (4). For simplicity, we use a simple cutoff specification that allows for different returns to experience according to whether a worker has "high" $(H)$ or "low" $(L)$ educational attainment, i.e. whether his years of schooling are larger or smaller than some cutoff $\bar{s}$ that is common across countries. We define the threshold to be at ten years of schooling, $\bar{s}=10$, which is approximately the average years of schooling in our set of countries, and also a cutoff for which we have sufficient observations above and below in all countries. When we plot the height of the experience-wage profile for workers with low schooling (less than ten years) against the height for those with high schooling (more than ten years), we find no systematic pattern between the steepness of profiles and educational attainment across countries.

Next, we conduct a similar counterfactual exercise as earlier and compute the implied experience-wage profile if all countries had the same share of highly educated individuals as the United States. We find that the relationship between the height of the counterfactual profiles and log GDP per capita is identical in the counterfactual and actual exercise, with a slope coefficient of 0.22 in each case. Thus, our results do not appear to be driven by differences in the composition of workers across countries by educational attainment.

Other Composition Effects. Using the same basic approach as above, we have explored composition effects along other dimensions that may differ systematically between rich and poor countries: services versus non-services, manufacturing versus non-manufacturing, public- versus private-sector employment, male versus female, urban versus rural, and fullversus part-time employment. We also explored compositional effects for different combinations of these categories. We find that none of these decompositions are important for explaining cross-country differences in the returns to experience. These results are not reported for brevity, and are available upon request.

\section{A.4 Measurement Error in Age or Schooling Data}

In Bangladesh and India, two of the poorer countries in our sample, we observe "age heaping" in the data, where individuals seem to be rounding their ages to the nearest five years. This is presumably due to survey respondents not knowing their true ages. Since measurement error in age may lead to attenuation bias in our estimated returns to experience, and since this problem may affect poor countries more than rich countries, one may be concerned that our cross-country finding is due to measurement error in age data. 
To investigate this further, we construct an auxiliary dataset for the United States in which we replace the age of a certain percentage of workers with their age rounded to the nearest five years. We then re-estimate the returns to experience with this auxiliary dataset. We find that even in the extreme case when we allow ninety percent of the U.S. population to mis-report their age, the profile is still far above that of (say) India. Thus, our main cross-country results are not driven by biases induced through age heaping.

One may have concerns about measurement error in schooling data as well since, in most countries, direct measures of the years that individuals spent in school are not available. We therefore rely on educational attainment data (e.g., "some secondary school" and "secondary school completed") in order to construct the "years of schooling" variable. Moreover, the coarseness of the educational attainment categories differs across countries.

To investigate this possibility further we create two auxiliary schooling variables for the United States and use them to re-estimate the U.S. experience-wage profile. The first auxiliary variable imputes schooling years using only information on degree attainment, such as primary school completion, secondary school completion, and so forth. This is similar to what we observe in some of the developing countries in our sample. The second auxiliary variable classifies secondary school graduates or higher as having twelve years of schooling and all others as having no schooling. This is meant to see how important an extreme amount of measurement error in schooling years may be. When we compute the actual and auxiliary profiles, however, we find that the differences are modest, and that the auxiliary profiles are slightly steeper than the actual ones. We conclude that our finding of flatter experience-wage profiles in poorer countries is unlikely to be driven by mismeasured years of schooling.

\section{A.5 Appendix to Section 5 "Evidence from U.S. Immigrants"}

Estimating Returns to Experience Using U.S. Immigrants. Our data on immigrants draw on the 1980-2000 U.S. Population Censuses as well as the 2005-2012 American Community Surveys (ACSs), downloaded via IPUMS. Each of these data sets includes a large, representative cross-section of the U.S. population in a particular year. We choose not to use data from earlier Censuses because their sample sizes were smaller (1 percent instead of 5 percent) and immigrants were a much smaller share of the population before 1980. The 2000 Census was the last to include a long form with detailed questionnaires sent to a subset of the population; the ACS, an annual 1 percent sample of the American population, is the successor to the Census long form. Most questions and responses were maintained in the transition, so that combining the data is straightforward.

We identify immigrants using country of birth. The Census and ACSs provide detailed responses that code the country of birth for most of the major source countries of U.S. immigrants. We aggregate only a few categories, mainly combining the subregions of the United Kingdom into a single country; otherwise, we maintain the Census responses. A possible complication when considering experience is that an immigrant's country of birth may not correspond to where they worked, if they migrated to a third country before immigrating to the United States. Fortunately, several years of the Census and the ACS ask also questions about where people lived one or five years prior to the Census. For those who were outside of the United States, we find that $87 \%$ report being in their birth country five years before migrating and $83 \%$ report being their one year before migrating. In an exercise that is available upon request, we also examined the relationship between 
this secondary migration and GDP per capita and find no systematic relationship.

Our data also includes information on the year of immigration, which we need to divide total potential experience into foreign (birth-country) and domestic (U.S.) potential experience. In the 1980 and 1990 Censuses this information was provided in ranges (e.g. 1975-1979). This category coding is unfortunate for our analysis because we want to compute years of foreign and domestic potential experience. We experiment with coding these ranges to the midpoint and using them in our analysis. We acknowledge that this will entail some small measurement error in foreign and domestic experience. To check whether this measurement error is critical for our results, we compare below the baseline results to those estimated using only data from 2000 onward, when the exact year of immigration is recorded (see Table A.2). We find that the results are quite similar.

We construct the hourly wage using information on annual wage and salary income for the prior year, usual hours worked per week, and weeks worked in the prior year. Weeks worked is coded into categories in 1980 and from 2008 onward. We use 1990 data to compute the average weeks worked per category in 1990 and impose this on the 1980 data; we use the 2007 data to compute the average weeks worked per category in 2007 and impose this on the 2008-2012 data. In 1980, income was top coded; we multiply all top-coded values by 1.4, in line with the literature. From 1990 onward, the Census replaces all top-coded values with the mean of state income within the top-coded group, so no adjustment is needed.

We limit our attention to countries with at least 1,000 immigrants that meet all the above sample restrictions. We want a relatively large sample of immigrants from each country because our preferred estimation allows for 18 country-specific parameters: four domestic experience terms; four foreign experience terms; four experience interaction terms; returns to schooling; an intercept; and four cohort-decade dummies. A large sample allows us to estimate precisely foreign experience profiles even with the flexibility implied by this parameter heterogeneity. An advantage of working with the pooled U.S. Censuses is that we maintain a large sample of over 1.5 million immigrants from 101 countries that meet this strong cutoff. Furthermore, these immigrants are drawn broadly from around the world. For example, we can estimate experience profiles for immigrants from 13 different African countries.

Robustness of Results for U.S. Immigrants. In this subsection, we explore the robustness of our stylized result shown in Figure 7 for immigrants to the details of our estimation procedure. We show that our results are not sensitive to these details: changing the sample selection criteria, looking at distinct subgroups, or changing the controls all yields a similar finding. A parsimonious way to show this fact is to focus on the regression lines plotted in that Figure. They capture the extent to which returns to experience vary with (the log of) GDP per capita in the birth country. Table A.2 displays the coefficient on log GDP per capita from these regressions. Focusing on the row "Baseline" shows that there is a statistically significant and positive relationship for immigrants who get both their schooling and experience abroad.

The remaining rows show the same results for alternative robustness checks. For each, we change our estimation in the listed manner; restrict our sample to countries with more than 1,000 immigrants in the modified sample; estimated the returns to foreign experience; calculate the height of the experience profile plotted at 20; and regress those heights against the log of PPP GDP p.c. The figure given is the slope of that estimated line. For example, the second row shows the relationship between steepness of experience profiles and birth 
country income is actually stronger if we limited our sample to only those with at least a college degree. The third and fourth rows show that our pattern prevails and is highly statistically significant if we focus on those with no more than a high school diploma or exclude those with advanced degrees. The fifth row shows that allowing for nonlinear returns to schooling (higher returns to a year of college than a year of non-college) for every country in the sample does not substantially alter our result.

The next five checks focus on subsamples defined by where they work. The pattern is weakened for those who work for the government, but is essentially the same for manufacturing and service industry workers; there are too few immigrants who work in agriculture to estimate a meaningful relationship. Likewise, the same pattern holds if we focus on immigrants who work in occupations that are commonly licensed or not; see Schoellman (2012) for the details of how this is constructed. The pattern also prevails if we focus on those who speak only English or speak English well; on heads of household, on men; or on those living outside of ethnic enclaves, defined as a public use micro data area with more than 5 percent of the population sharing the same birth country or a metropolitan area with more than 2.5 percent of the population sharing the same birth country; these restrictions eliminate around one-third of immigrants from our sample. Our results go through, indicating that ethnic enclaves do not drive our results. We use only the data from 2000 and onward, which may be interesting because for these years the year of immigration is coded as the exact year rather than an interval; the results are essentially identical to the baseline. Finally, we try excluding some of the control variables and find that does not change our results.

Identification Issues for U.S. Immigrants. This subsection briefly discusses the assumptions needed to identify returns to experience for immigrants. The discussion borrows heavily from the classic work by Borjas (1985) and Friedberg (1992).

The first identification issue has to do with a linear dependency between domestic experience, dataset year, and year of arrival: domestic experience is defined as dataset year minus year of arrival. This means that we cannot estimate all three effects separately without further assumptions. We follow Borjas (1985) by including natives and restricting year effects to be the same for natives and immigrants. The underlying assumption is that time effects capture aggregate economic conditions such as recessions or inflation that affect immigrants and natives equally. In this case, natives allow us to identify the time effects; we can then identify the effects of year of arrival and domestic experience using immigrants.

The second identification issue arises in a more general framework than we use in the text. While our specification includes a number of country-specific effects, we exclude two considered elsewhere, namely, assimilation effects (measured as years spent in the U.S.) and age-at-arrival effects (intended to capture adaptability) (Friedberg, 1992).

Each of these effects is collinear with the effects included in our model. Years in the United States is the same as U.S. experience; each is calculated as the gap between year of arrival to the U.S. and dataset year. Here, we have to acknowledge that it is not clear whether our estimated effects of domestic experience actually represent experience or a broader effect of assimilation. However, this distinction is not central to our study, which concern the return to foreign experience. Age at arrival is closely related to foreign experience: they differ only by the expected age at graduation. Once again, the implication is that it is difficult to distinguish between the effects of foreign experience and a more general effect for age at arrival due to, say, adaptability. However, given that our estimated 
experience profiles for immigrants look strikingly similar to the estimated profiles for nonmigrants, one natural interpretation is that the dominant effect can be attributed to foreign experience.

\section{A.6 Human Capital, Selection and Skill Loss: A Simple Model}

Here, we present a simple model to make two points. The first is a more precise statement of what exact forms of selection and skill loss discussed in 5.5 can explain our immigrant findings, and which ones cannot. The second is a more precise statement of the argument that low human capital accumulation in poor countries is the only factor that can simultaneously explain our findings on stayers and immigrants. Individuals are indexed by $i$, countries by $c$. An individual may work either in his country of origin, acquiring foreign experience or in the United States, acquiring U.S. experience. We denote variables observed in the U.S. with asterisk superscripts. Within each country of origin, individuals are heterogeneous in their initial human capital $\eta_{i c}$ and their learning ability $z_{i c}$. We assume that $\mathbb{E}\left[\eta_{i c}\right]=\mathbb{E}\left[z_{i c}\right]=1$ for all $c$ but migrants may be a selected part of the population. We further denote by $x_{i c}(t)$ and $x_{i c}^{*}(t)$ the amount of home-country and U.S. experience an individual has accumulated up to time $t$. If an individual works in his home country his human capital accumulates passively according to

$$
\dot{h}_{i c}(t)=z_{i c} \phi_{c}\left(x_{i c}(t)\right) h_{i c}(t),
$$

with $h_{i c}(0)=\eta_{i c}$, and when he works in the U.S. it accumulates according to $\dot{h}_{i c}^{*}(t)=$ $z_{i c} \phi_{c}^{*}\left(x_{i c}^{*}(t)\right) h_{i c}^{*}(t)$. We allow for the possibility that "human capital accumulation technologies" differ across countries, and that, upon arrival in the U.S., immigrants gain access to a different technology. The wage of individual $i$ from country $c$ with $x$ years of homecountry experience is

$$
w_{i c}(x)=\omega_{c}\left(1-\tau_{c}(x)\right) h_{i c}(x) e^{\varepsilon_{i c}},
$$

where $\omega_{c}$ is the skill price in country $c$ and $\tau_{c}$ is a wedge that captures country-specific labor market institutions. Similarly, the wage of immigrant $i$ from country $c$ with $x$ years of home-country experience and $x^{*}$ years of U.S. experience is $w_{i c}^{*}\left(x, x^{*}\right)=\omega_{c}^{*}(1-$ $\left.\tau^{*}(x)\right) h_{i c}^{*}\left(x, x^{*}\right) e^{\varepsilon_{i c}}$.

At some level of home-country experience $x$, workers from country $c$ migrate to the U.S.. Part of a individual's human capital may be country-specific and therefore lost upon migration: human capital after migration is $h_{i c}^{*}=m_{c}\left(h_{i c}\right) h_{i c}$ where $m_{c}\left(h_{i c)} \leq 1\right.$. It turns out to be convenient to assume the functional form $m_{c}\left(h_{i c}\right)=\gamma_{c} h_{i c}^{\theta_{c}-1}$ so that human capital upon arrival in the U.S. is $h_{i c}^{*}=\gamma_{c} h_{i c}^{\theta_{c}}$. The parameter $\gamma_{c}>0$ captures the average "skill loss" incurred by a migrant from country $c$. The parameter $\theta_{c}>0$, in contrast captures whether skill loss is more of a problem for high human capital types. There may also be selection upon migration: denoting the set of individuals with experience level $x$ who migrate from country $c$ to the U.S. by $M_{c}(x)$ we allow for the possibility that $\mathbb{E}\left[\eta_{i c} \mid i \in M_{c}(x)\right] \neq \mathbb{E}\left[\eta_{i c}\right]=1$ and $\mathbb{E}\left[z_{i c} \mid i \in M_{c}(x)\right] \neq \mathbb{E}\left[z_{i c}\right]=1$. Note that we allow for fairly general types of selection: there may be selection on both initial ability $\eta_{i c}$ and learning ability $z_{i c}$, and furthermore both types of selection may differ with the level of experience.

Given our assumptions, human capital of stayers can be solved in closed form and satisfies $\log h_{i c}(x)=\log \eta_{i c}+z_{i c} \int_{0}^{x} \phi_{c}(y) d y$ and a similar expression for immigrants. Com- 
bining with (32), the wages of stayers and of new immigrants, i.e. those with zero years of U.S. experience $x^{*}=0$, are

$$
\begin{aligned}
\log w_{i c}(x) & =\log \omega_{c}+\log \eta_{i c}+\log \left(1+\tau_{c}(x)\right)+z_{i c} f_{c}(x)+\varepsilon_{i c} \\
\log w_{i c}^{*}(x, x) & =\log \omega_{c}^{*}+\log \gamma_{c}+\log \eta_{i c}+\log \left(1+\tau^{*}(x)\right)+\theta_{c} z_{i c} f_{c}(x)+\varepsilon_{i c}
\end{aligned}
$$

where we denote by $f_{c}(x)=\int_{0}^{x} \phi_{c}(y) d y$ the cumulative returns to home-country experience. The regressions we run using data on stayers and immigrants are

$$
\begin{aligned}
& \log w_{i c}=\alpha_{c}+R_{c}\left(x_{i c}\right)+\varepsilon_{i c}, \quad R_{c}(x)=\log \left(1-\tau_{c}(x)\right)+f_{c}(x) \\
& \log w_{i c}^{*}=\alpha_{c}+R_{c}^{*}\left(x_{i c}\right)+\varepsilon_{i c}, \quad R_{c}^{*}(x)=\mathbb{E}\left[\log \eta_{i c} \mid i \in M_{c}(x)\right]+\log \left(1+\tau^{*}(x)\right)+\theta_{c} \mathbb{E}\left[z_{i c} \mid i \in M_{c}(x)\right] f_{c}(x)
\end{aligned}
$$

The measured return to stayers' experience $R_{c}(x)$ may differ across countries because of country-specific labor market institutions $\tau_{c}$ or cross-country differences in human capital accumulation $f_{c}$. The measured returns to immigrants' home country experience $R_{c}^{*}(x)$ may differ across source countries for one of four reasons: first, human capital accumulation $f_{c}$; second, experience-dependent selection on initial ability, i.e. $\mathbb{E}\left[\log \eta_{i c} \mid i \in M_{c}(x)\right]$ decreases with $x$; third, selection on learning ability; fourth, experience-dependent skill loss, $\theta_{c}<1$.

Our first point is that only the types of selection and skill loss just mentioned can explain low immigrant returns. In contrast, selection on initial ability that is not experiencedependent (i.e. $M_{c}(x)=M_{c}$ with $\mathbb{E}\left[\log \eta_{i c} \mid i \in M_{c}\right]<1$ ) and skill-loss that is not experience-dependent and $\left(\gamma_{c}<1\right)$ cannot explain this fact. These simply show up as country fixed effects $\alpha_{c}$. Furthermore section 5.5 provides evidence against the importance of the types of selection and skill loss that can explain the facts. Our second point, which can be seen clearly from the two equations, is that human capital accumulation $f_{c}$ is the only factor that can simultaneously explain low measured returns to experience for both stayers and U.S. immigrants.

\section{A.7 Comparison of Development Accounting Results to Literature}

We now summarize our development accounting results by illustrating the effects of each departure that we take from existing accounting exercises and their influences on our final result. The results are shown in Table A.1, and all results use our data. We begin, in Panel (a), with a specification similar to the one used by Klenow and Rodriguez-Clare (1997), and proceed step-by-step to the specification in our benchmark exercise, in Panel (e), making one change at a time.

The specification in Panel (a) of Table A.1 computes human capital stocks using a linear-quadratic Mincer specification and the average returns to schooling and experience as in Klenow and Rodriguez-Clare (1997). The first column presents the dispersion of human capital across countries, measured as the variance of the logarithm of the stock of countryspecific human capital. The second column presents Success $s_{1}$. It shows that taking human capital due to both schooling and experience into account produces a measure of 0.44, which is similar to the value of 0.39 reported in Caselli (2005).

Panel (b) of Table A.1 uses the same specification, but imposes diminishing returns to schooling as in Hall and Jones (1999). This is also similar to Bils and Klenow (2000). 
Success $s_{1}$ is essentially unchanged at 0.42 . Panel (c) allows returns to experience to vary across countries, but retains the quadratic specification for estimating the returns to experience. This increases success $s_{1}$ from 0.42 to 0.51 . Panel (d) allows the returns to experience to vary across countries and uses our main quintic functional form for estimating the returns to experience. This causes success $s_{1}$ to further increase from 0.51 to 0.63. Panel (e) additionally allows returns to schooling to vary across countries (estimated using a linear control for the years of schooling). This produces our main results shown in Table 4: success $_{1}$ is 0.63 .

\section{A.8 Ben-Porath Model of Human Capital Accumulation}

To measure human capital stocks through the lens of the Ben Porath model of Section 7.2 , we proceed as follows. Given $h(0)=1$, the human capital at experience level $x$ is $\log h(x)=\int_{0}^{x} \phi(\ell(s)) d s$. Since $w=\bar{\omega}(1-\ell) h \exp (\varepsilon)$, the wage regression is

$$
\log w=\log (\bar{\omega}(1-\ell(0)))+\log \left(\frac{1-\ell(x)}{1-\ell(0)}\right)+\int_{0}^{x} \phi(\ell(s)) d s+\varepsilon .
$$

As mentioned above, we assume that the technology $\phi$ is known and the same across all countries, and that all cross-country variation in investment decisions is driven by the wedge $\tau(t)$. The time allocation, $\ell(x)$, can then be identified as follows. First, we have an experience-wage profile $f(x)$ from the data, and we know that:

$$
f(x)=\log \left(\frac{1-\ell(x)}{1-\ell(0)}\right)+\int_{0}^{x} \phi(\ell(s)) d s .
$$

Differentiating and rearranging, we obtain:

$$
\ell^{\prime}(x)=\left[\phi(\ell(x))-f^{\prime}(x)\right](1-\ell(x))
$$

In any Ben-Porath model, it will be true that just before retirement at $x=T$, people do not invest in human capital: $\ell(T)=0$. So given functions $f(x)$ and $\phi(\ell)$, this is a simple differential equation in $\ell(x)$ with a terminal condition at $\ell(T)=0$. It can be solved very efficiently with a finite difference method. 
Table A.1: Relation to Literature

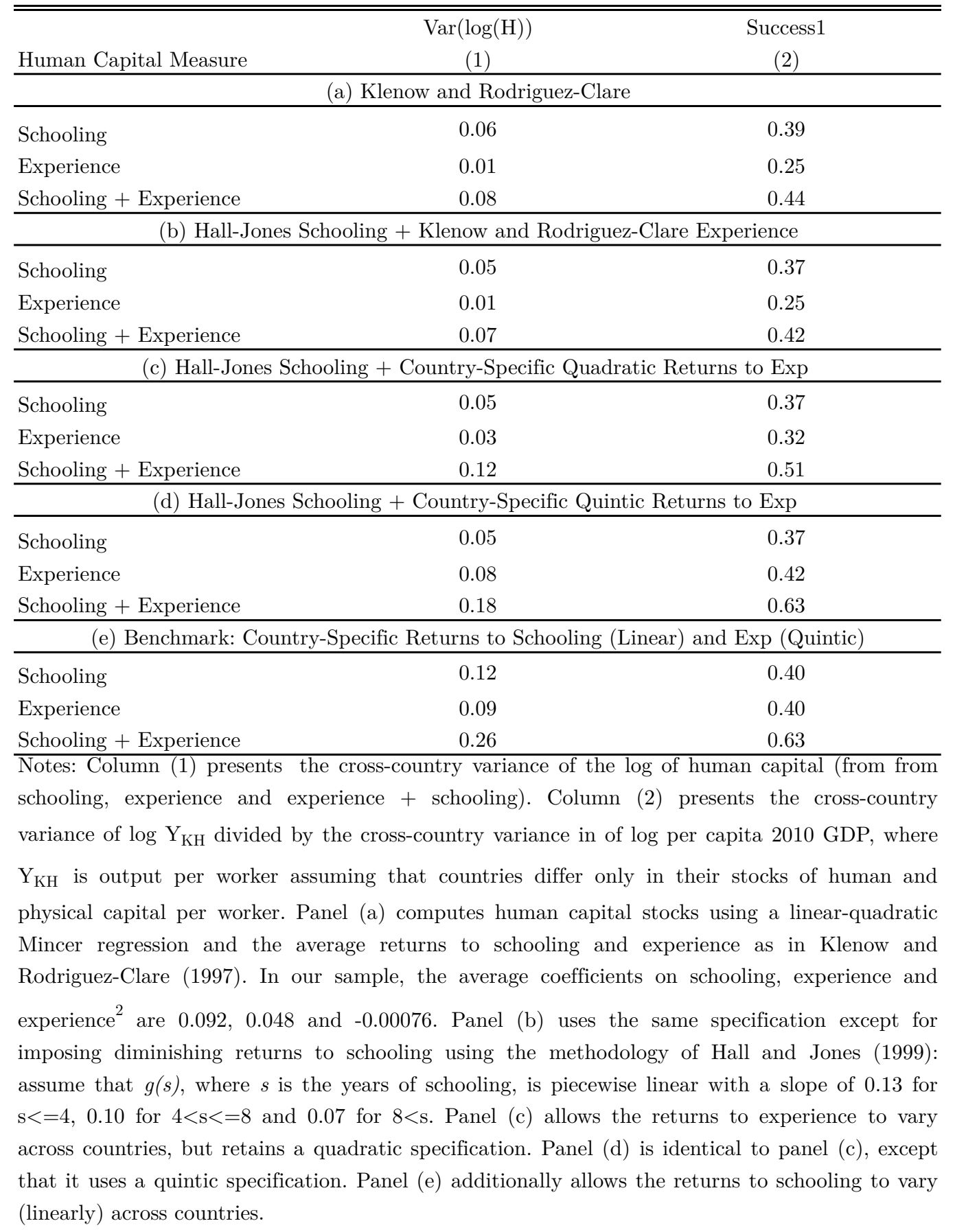


Table A.2: Returns to Immigrant Experience and GDP per capita: Robustness

\begin{tabular}{lcc}
\hline \hline Sample & Estimate & Standard Error \\
\hline Baseline & 0.200 & 0.024 \\
\hline College Graduate or More & 0.241 & 0.037 \\
High School Graduate or Less & 0.146 & 0.030 \\
No Advanced Degress & 0.145 & 0.027 \\
Nonlinear School & 0.198 & 0.031 \\
Public Employee & 0.137 & 0.060 \\
Manufacturing & 0.222 & 0.052 \\
Service Industry & 0.180 & 0.026 \\
Licensed Occupation & 0.111 & 0.056 \\
Unlicensed Occupation & 0.193 & 0.046 \\
Excellent English & 0.208 & 0.024 \\
Head of Household & 0.232 & 0.031 \\
Men & 0.196 & 0.026 \\
No Ethnic Enclaves & 0.188 & 0.027 \\
Year 2000+ & 0.188 & 0.026 \\
No State, Gender Controls & 0.218 & 0.026 \\
\hline Note: Each row in the table represents the slope coefficient and its standard error \\
from a regression of the estimated returns to twenty years of potential experience on \\
GDP per capita.
\end{tabular}


Figure A.1: Returns to Experience in Agriculture and Non-Agriculture

(a) Height of Profiles at 20 Years of Experience by Sector

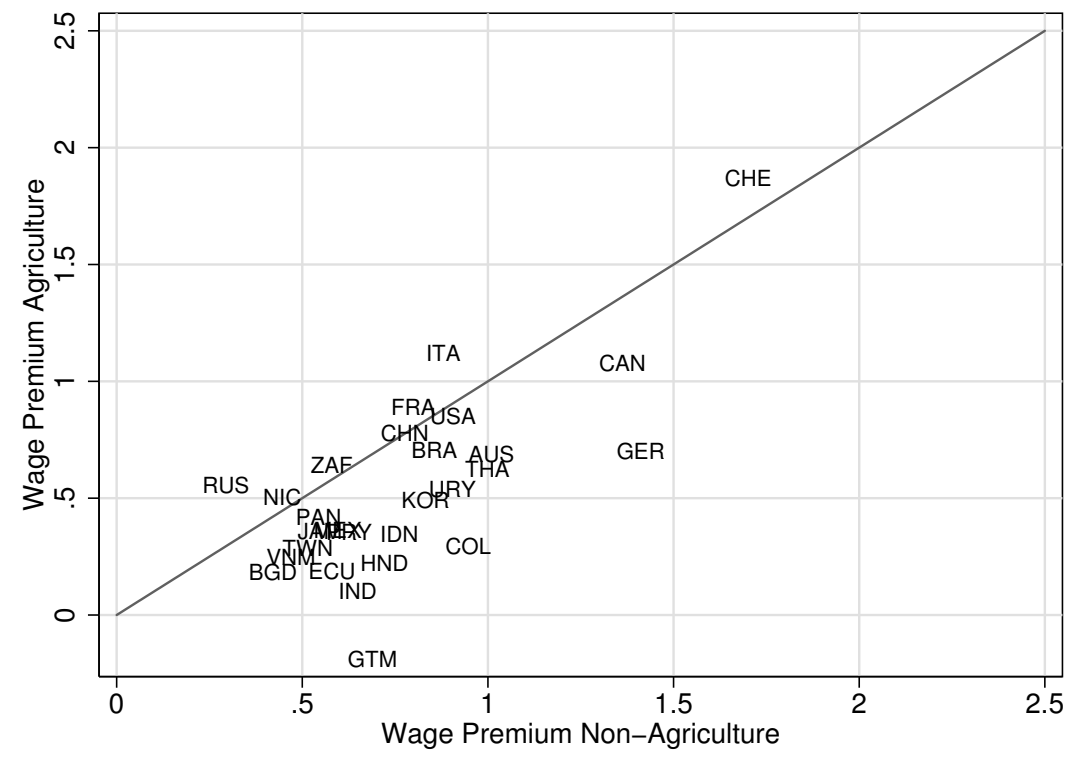

(b) Counterfactual: U.S. Employment Share in Agriculture

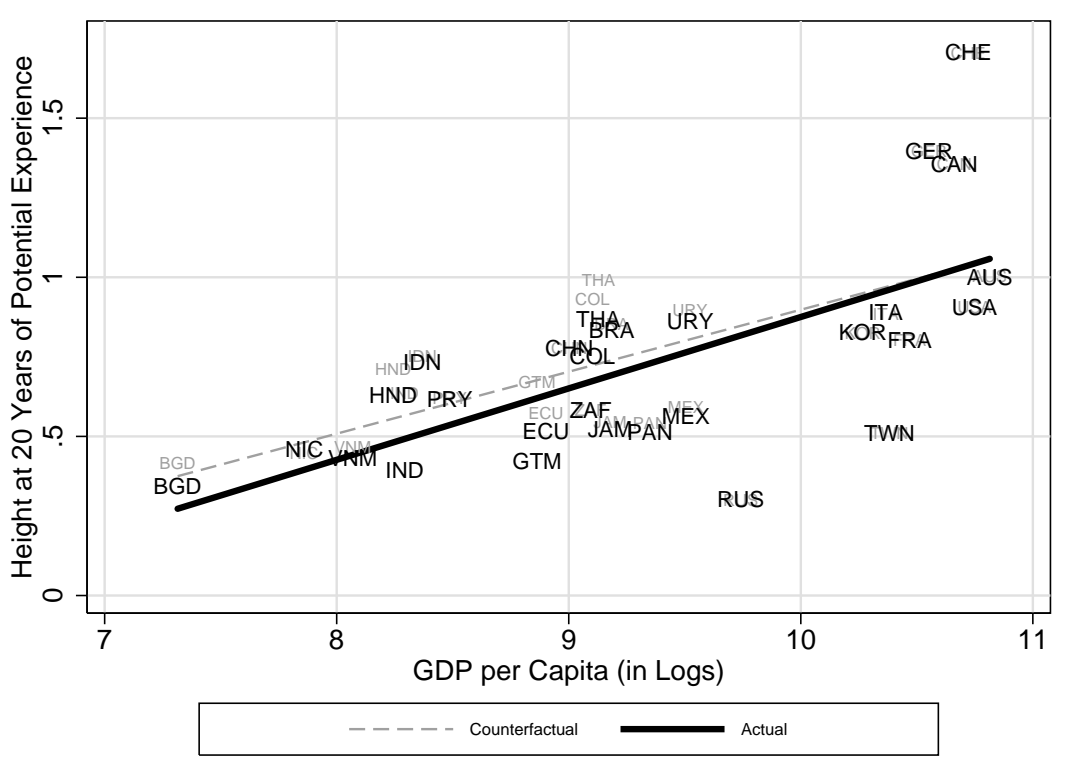



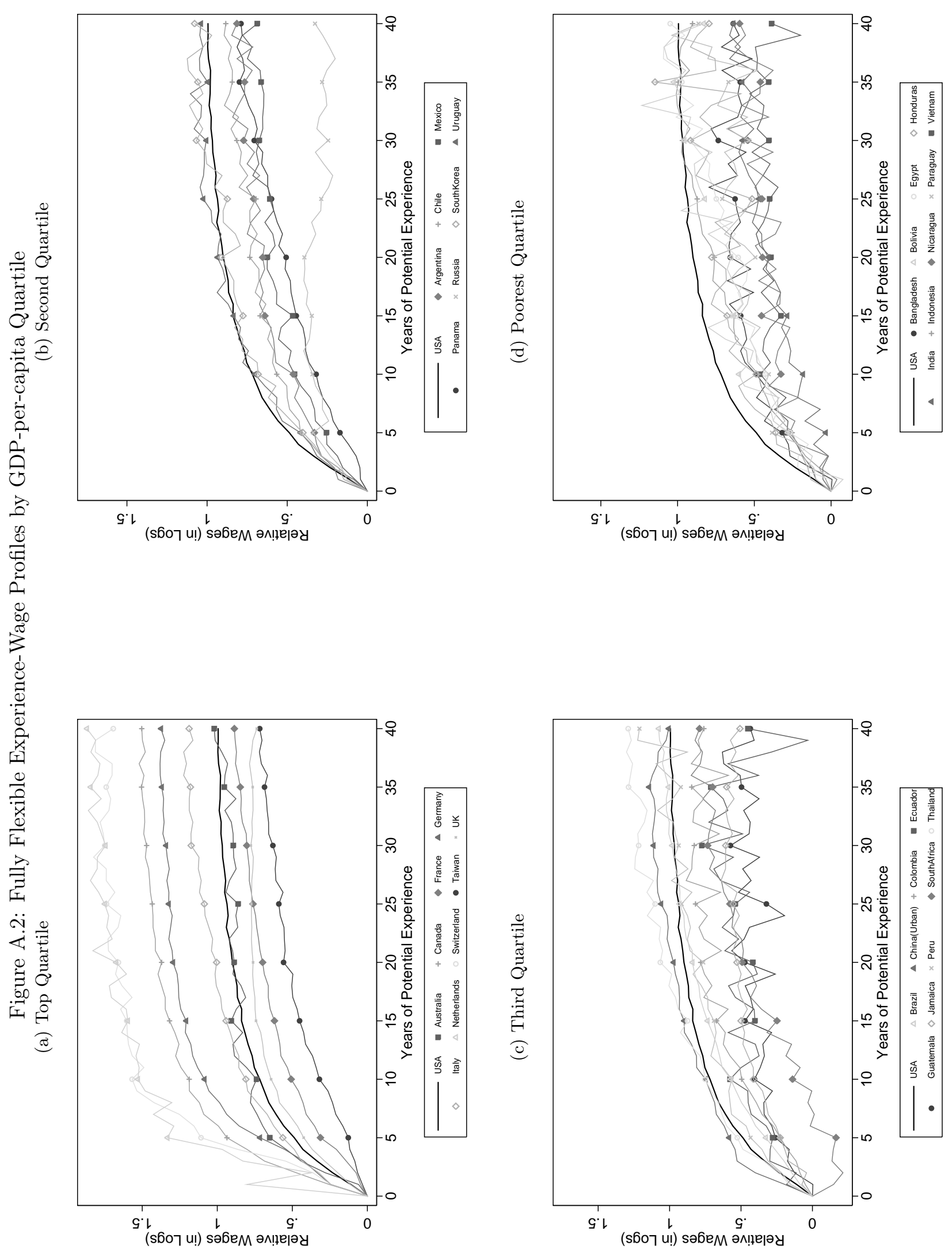
Figure A.3: Fully Flexible Experience-Wage Profiles with Confidence Intervals

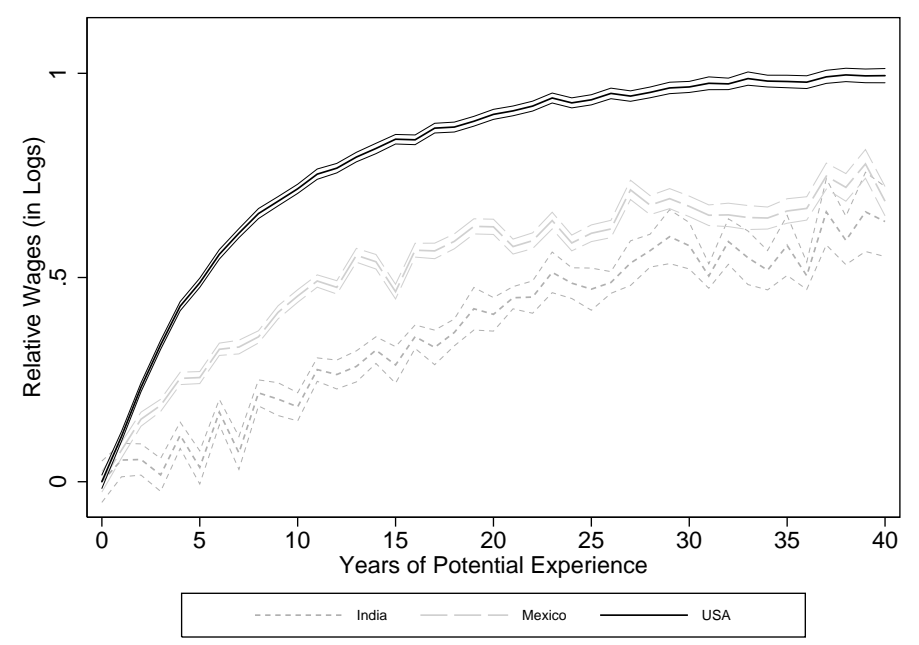

Figure A.4: Fraction of Individuals with Positive Wages by Age

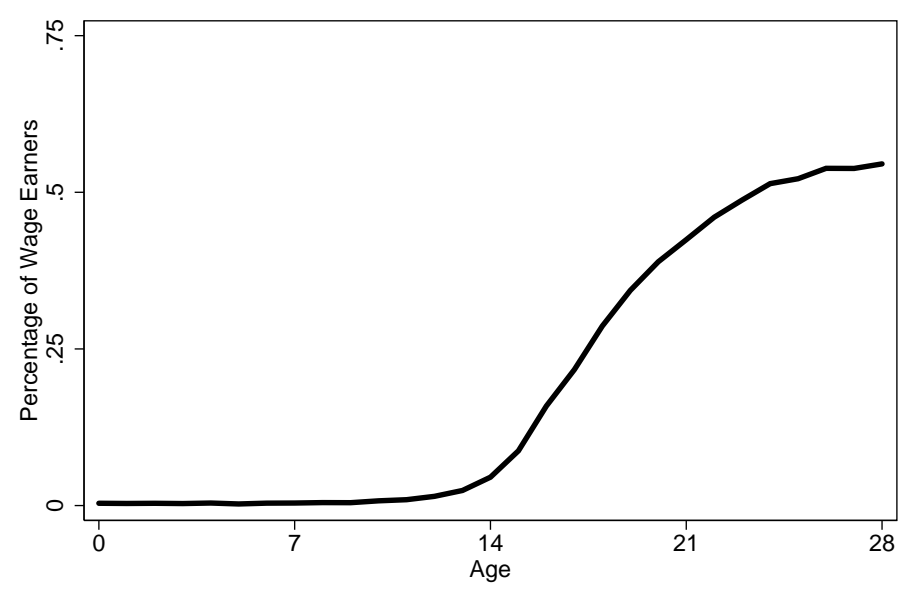

Figure A.5: Returns to Experience Including the Self-Employed

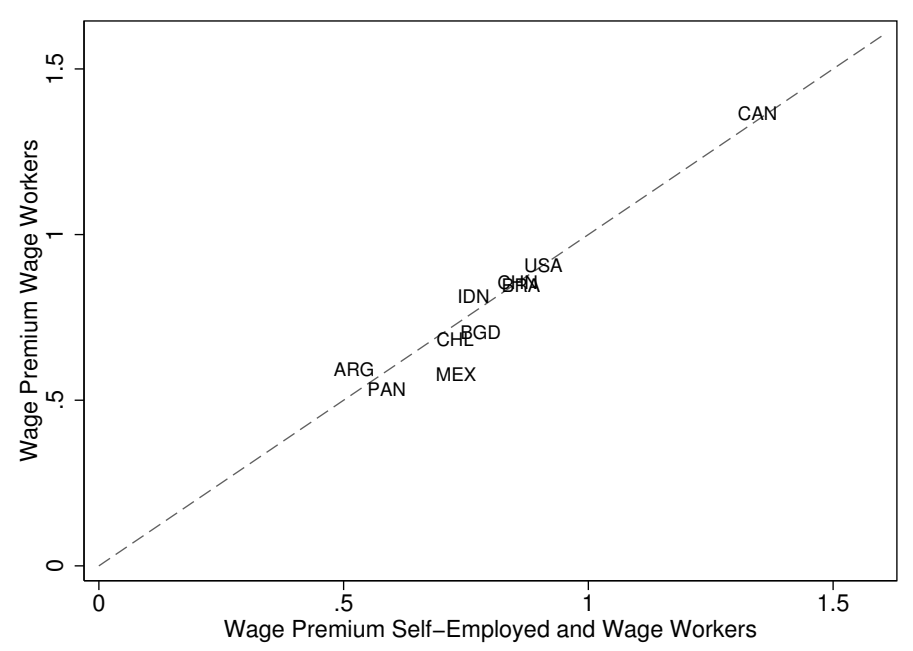


Figure A.6: Deaton-Hall Estimates for China: All Growth Due to Cohort Effects
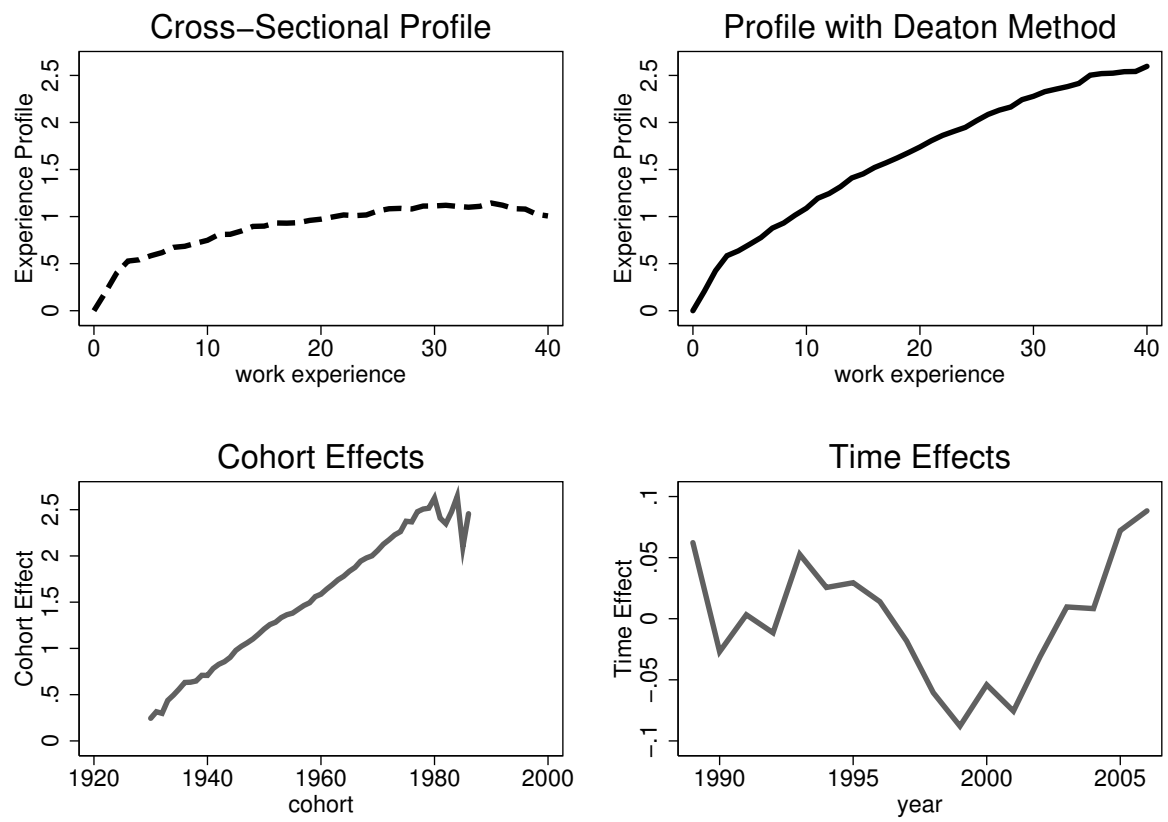

Figure A.7: Deaton-Hall Estimates for China: All Growth Due to Time Effects
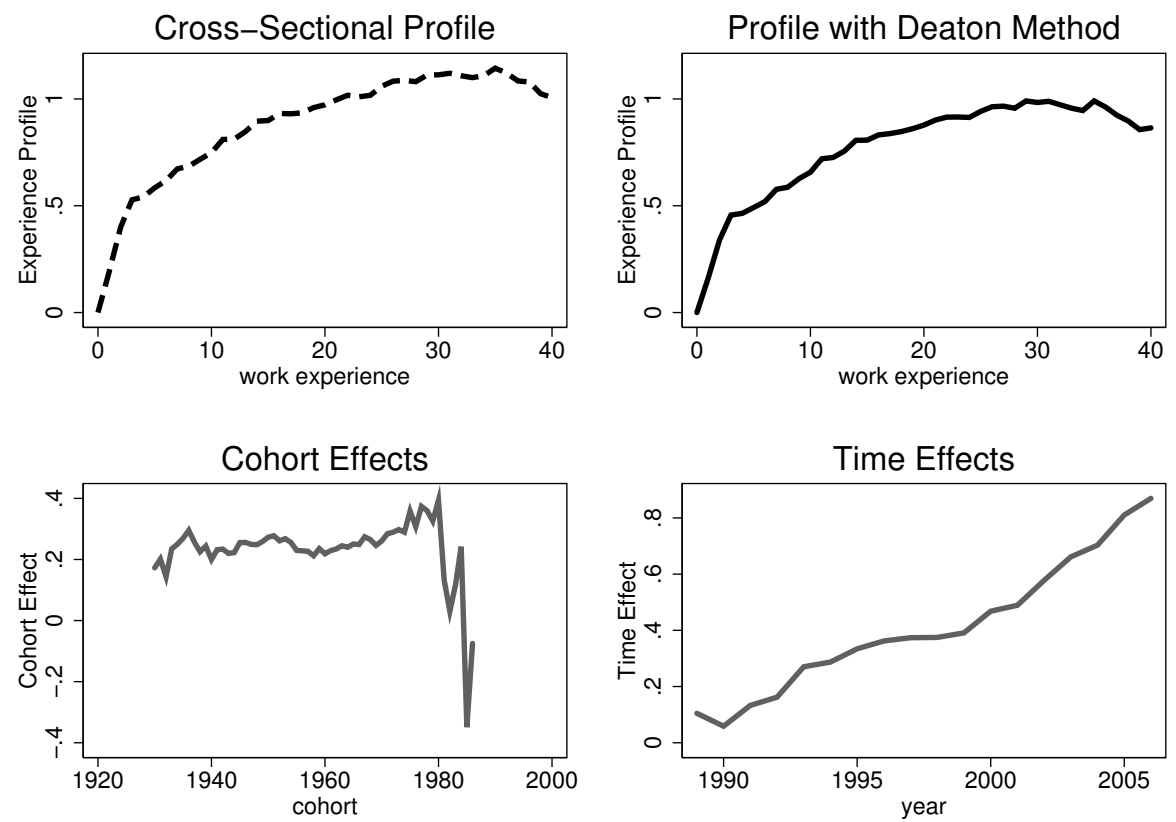
Figure A.8: Estimated Returns to Schooling versus GDP per capita

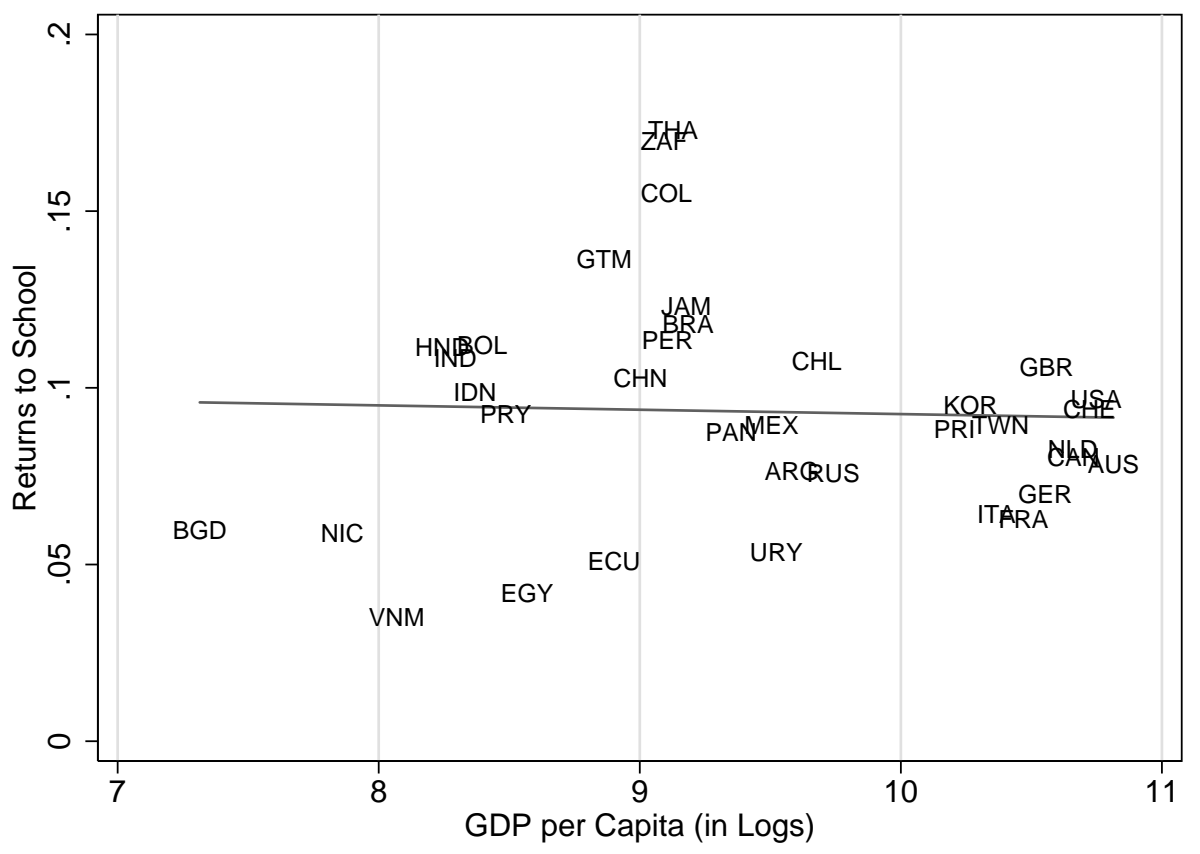

Figure A.9: Average Experience versus GDP per capita

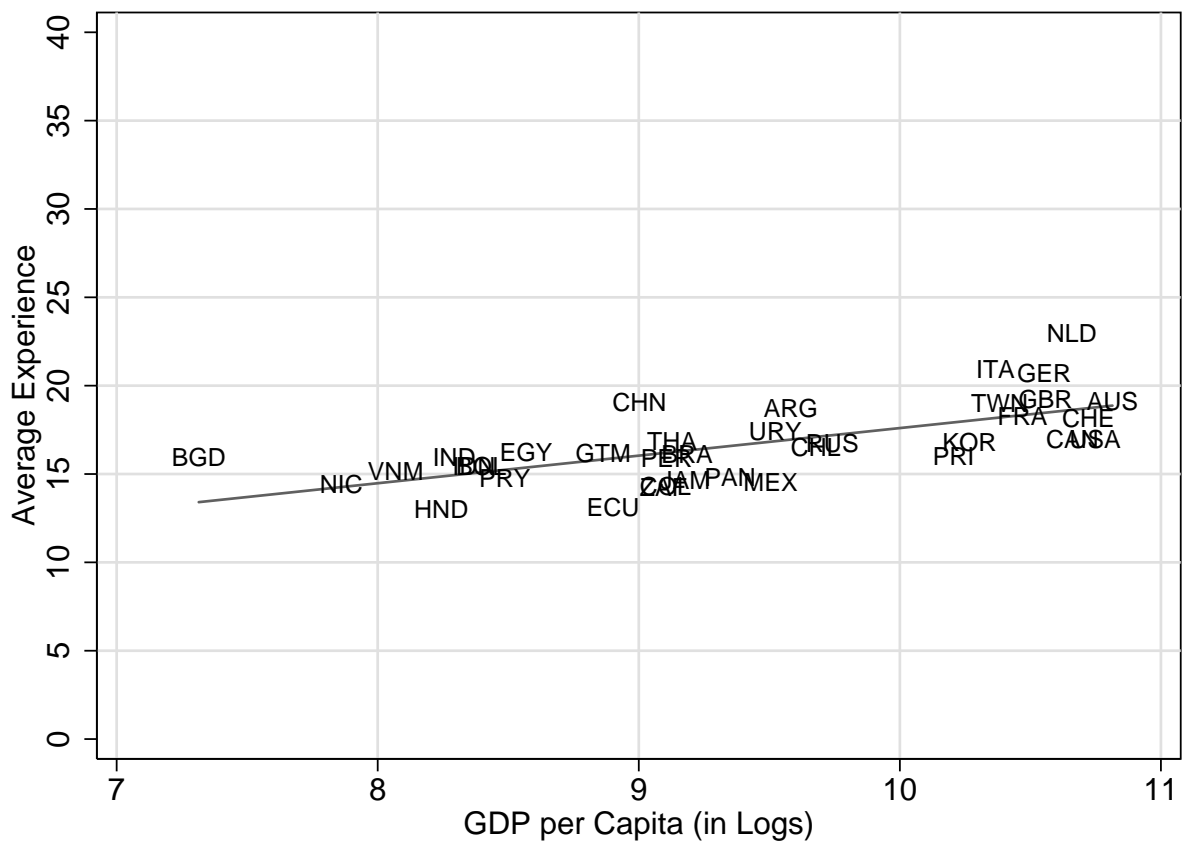


Figure A.10: Wages, Human Capital and Investment in Ben-Porath Model

(a) Profile of Investment

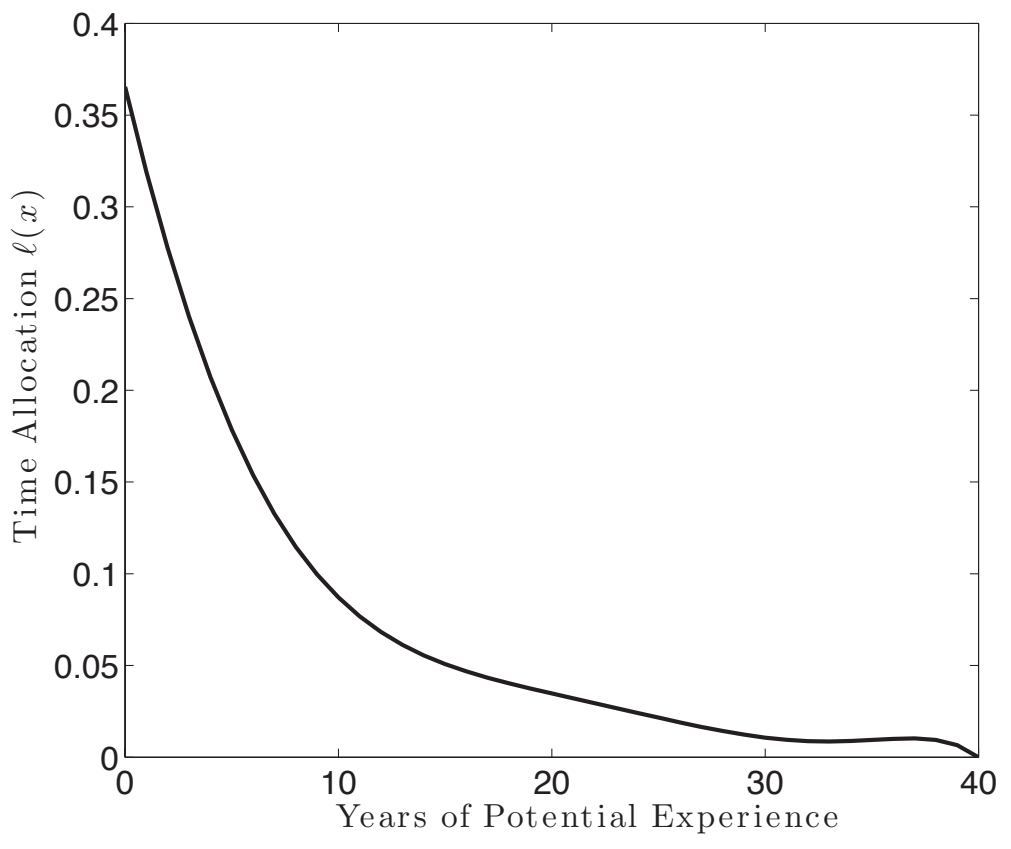

(b) Profiles of Wages and Human Capital

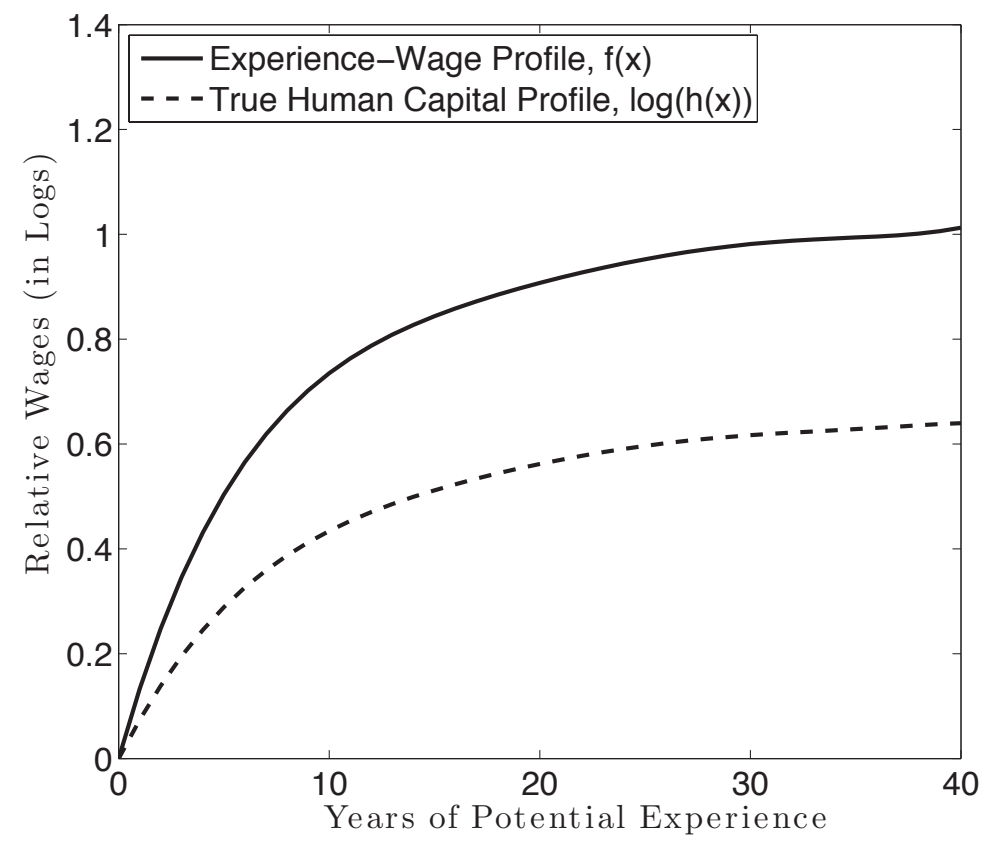


Figure A.11: Height of Experience-Earnings Profiles versus GDP per capita

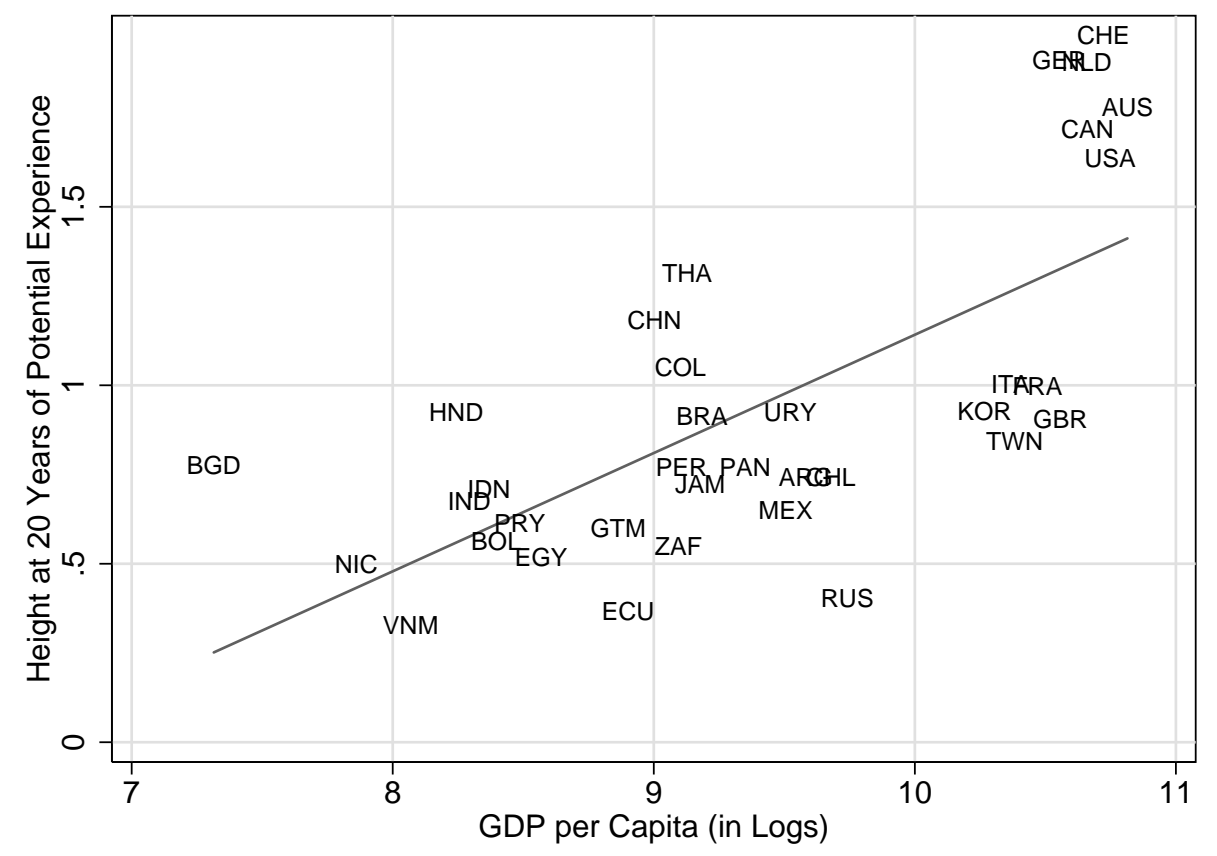

Figure A.12: Height of Age-Wage Profiles versus GDP per capita

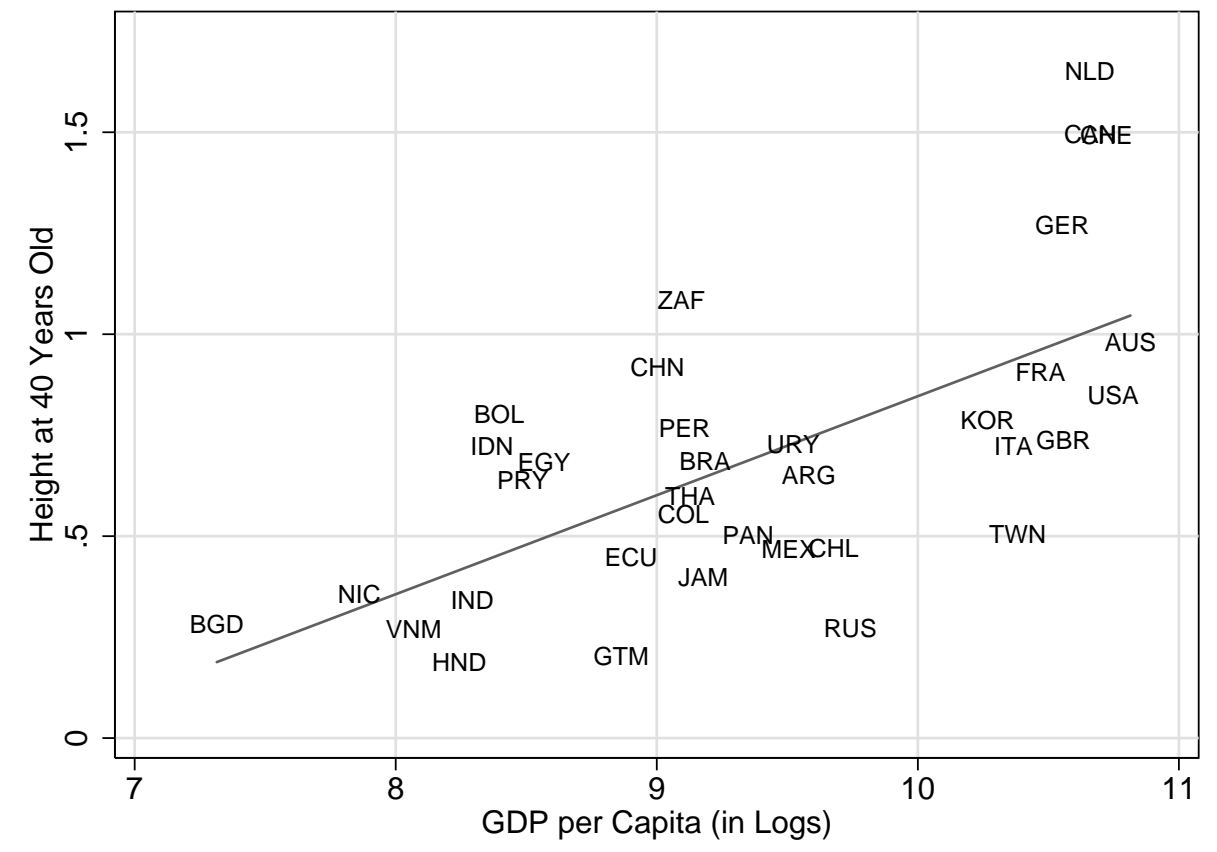

